Tjalling C. Koopmans Research Institute Tplligl Aoopman

Discussion Paper Series nr: 03-04

\title{
Permanent and Transitory Wage Inequality of British Men, 1975-2001: Year, Age and Cohort Effects
}

Adriaan S. Kalwij Rob Alessie 


\section{Tjalling C.Koopmans Research Institute Utrecht School of Economics Utrecht University}

Vredenburg 138

3511 BG Utrecht

The Netherlands

telephone (0031) 0302539800

fax (0031) 0302537373

website www.koopmansinstitute.uu.nl

The Tjalling C. Koopmans Institute is the research institute and research school of the Utrecht School of Economics.

It was founded in 2003, and named after Professor Tjalling C. Koopmans, the Dutch born Nobel Prize laureate in economics in 1975.

In the discussion papers series the Koopmans Institute publishes results of ongoing research for early dissemination of research results, and to enhance discussion with colleagues.

Please sent any remarks or questions on the Koopmans

institute, or this series to P.vanDriel@econ.uu.nl

ontwerp voorblad: WR IK Utrecht

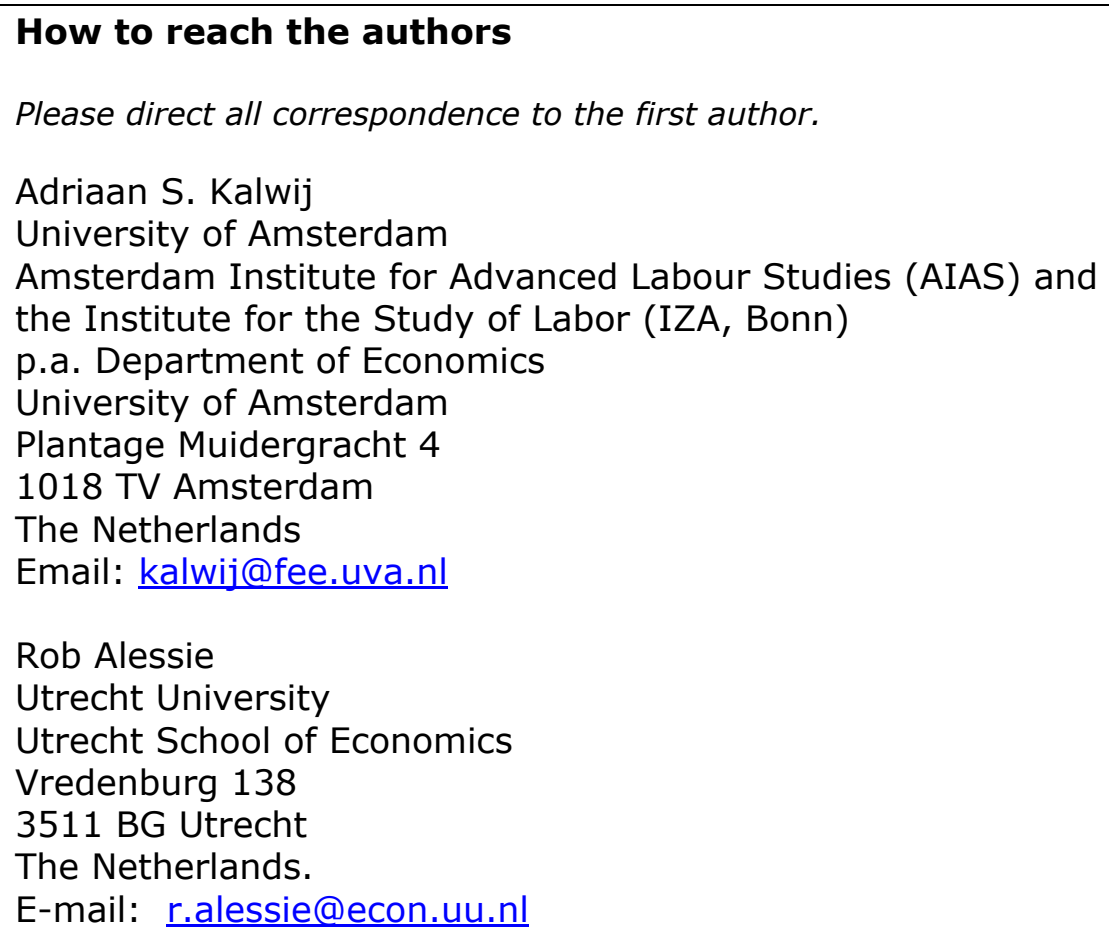




\title{
Permanent and Transitory Wage Inequality of British Men, 1975-2001: Year, Age and Cohort Effects
}

\author{
Adriaan S. Kalwija \\ Rob Alessie ${ }^{b}$
}

aniversity of Amsterdam, Amsterdam Institute for Advanced Labour Studies (AIAS)

bUtrecht School of Economics Utrecht University

July 2003

\begin{abstract}
We examine the variance-covariance structure of log-wages over time and over the lifecycle of British men from 1975 to 2001, hereby controlling for cohort effects. Wage inequality has risen sharply during the 1980's and early 1990's and remained fairly constant in the second half of the 1990's. We show that this increase is caused mainly by a strong increase in the transitory wage inequality and only to a lesser extent to an increase in the permanent wage inequality. The transitory component of wages is, however, highly persistent over time: serial correlation decreases from 0.88 over a one-year period to 0.65 over a ten-year period. The constant wage inequality in the second half of the 1990's is attributed to a slight decrease in permanent wages inequality, a stabilization of the variance of the transitory wage shock, and the strong decrease in the transitory wage inequality for the cohorts entering employment since the end of the 1980's. Ignoring age effects in transitory wage inequality and cohort effects, as is commonly done, leads to severely distorted inferences concerning the changes in permanent wage inequality.
\end{abstract}

Keywords: Panel Data, Wage Distribution, Inequality, Mobility

JEL classification: C23 D31, J31, J60

\section{Acknowledgements}

We wish to thank the seminar participants at Nuffield College (University of Oxford), the Tinbergen Institute (University of Amsterdam), Amsterdam Institute for Advanced Labour Studies and the 2003 Meeting of the European Society of Population Economics for valuable comments, and Nigel Stuttard at National Statistics for providing the NES data. Financial support from the Leverhulme Trust project "The labour market consequences of technical and structural change" is gratefully acknowledged. Please direct all correspondence to the first author. 


\section{Introduction}

One of the striking features of the British labour market from the mid 1970's onwards is the strong increase in wage inequality. Gosling et al. (2000) report that the gap between the $10^{\text {th }}$ and $90^{\text {th }}$ percentile of the wage distribution changed little during the 1960 's and early 1970 's and has widened rapidly throughout the 1980's and early 1990's. Dickens (2000a) reports a doubling of the variance of the logarithm of hourly wages from 1975 to 1995 . Ramos (2003), using the 1991-1999 British Household Panel Study, shows relative stable earnings inequality from 1994 to 1997, a decrease from 1997 to 1998 and a sharp increase from 1998 to 1999. In contrast, Gosling and Lemieux (2001), using the Family Expenditure Survey and Labour Force Survey, report that wage inequality in the U.K. remained relatively stable throughout the second half of the 1990's. In these respects the British labour market shows trends similar to the U.S. labour market (Katz and Autor, 2000, Gosling and Lemieux, 2001). Other industrialised countries have experienced similar changes in the wage distribution over the last decades but the increase in wage inequality over time is much less pronounced than in Britain and the U.S. or even absent during the 1980's for countries such as (West) Germany. A cross-country comparison of wage inequality can be found in Gottschalk and Smeeding (1997), Katz and Autor (2000) and Acemoglu (2002). ${ }^{1}$

Disentangling variances of the permanent and transitory wage components plays a key role in understanding the changes in the wage distribution over time (Lillard and Willis, 1978, Gottschalk, 1982, Atkinson et al., 1992, Gottschalk and Moffitt, 1994, Moffitt and Gottschalk, 2002, Cappellari, 2003). For instance, the relative importance of the permanent

\footnotetext{
${ }^{1}$ Gottschalk and Joyce (1998), Snower (1999) and Katz and Autor (2000) provide excellent discussions on the possible explanations suggested in the literature for this rise in inequality, such as skill biased technological change, and the different patterns of earnings inequality over time across countries.
} 
wage component is closely related to the earnings mobility of individuals; defined as the probability individuals change ranks within the wage distribution. Moffitt and Gottschalk (1995) show that in a canonical permanent-transitory (log-) earnings component model, and under normality assumptions, wage mobility depends solely on the ratio of the variance of the permanent component of wages and total wage variation: an increase in the ratio results in a decrease in wage mobility. ${ }^{2}$

All pioneering studies mentioned above employ U.S. data but more recently empirical evidence has been gathered for Britain. Blundell and Preston (1996, 1998) use the British Family Expenditure Survey (FES) for this purpose. Since the FES is not a panel, they have to rely on other information to separately identify the growth in the variances of permanent and transitory income shocks. They use consumption data for this purpose. In doing so, they exploit the fact that an increase in the short-run variation of transitory income does not affect lifecycle income, hence the consumption of households. ${ }^{3}$ A sufficient condition for this to be true is that the Permanent-Income Hypothesis holds. They conclude that there has been a strong growth in transitory income inequality in the late 1980's and early 1990's, while younger cohorts appear to face higher levels of permanent income inequality. Dickens (2000a), using the New Earnings Survey (NES), builds on the models proposed by MaCurdy (1982) and Moffitt and Gottschalk (1995). He concludes that the variance of the permanent component of wages has risen in the early 1980's and the variance of the transitory component of wages has risen in the late 1980's, each explaining about half of the rise in

\footnotetext{
${ }^{2}$ Methods of analysing earnings mobility more explicitly using other econometric techniques, such as transition models, are discussed in Sloane and Theodossiou (1996), Jarvis and Jenkins (1998), Buchinsky and Hunt (1999) and Dickens (2000b). Atkinson et al. (1992) provides an overview of many of these techniques and excellent discussions on inequality and mobility.

${ }^{3}$ See also Attanasio, Berloffa, Blundell and Preston (2002).
} 
wage inequality in Britain over the period 1975-1995. Ramos (2003), using the British Household Panel Study and a model in the spirit of Baker and Solon (2003), concludes that earnings persistence has fallen and, consequently, mobility has increased over the period 1991-1999.

The main objective of this study is to examine the changes in the variances of the transitory and permanent components of the logarithm of gross hourly wages of British men over the years 1975-2001. For this purpose we use the New Earnings Survey, which is the same data used by Dickens (2000a). This study contributes significantly to the literature from both an empirical and a methodological perspective in the following way: We examine the change in wage inequality in Britain up to 2001 . The fact we have recent data is particularly interesting because the rise in wage inequality appears to have come to a halt in the second half of the 1990's. By means of the minimum distance method, we estimate several econometric models developed in the literature so far for analysing the variance-covariance structure of wages; among those models that are very similar to the ones used by Dickens (2000a) and Moffitt and Gottschalk (2002). All of these models do not pass a goodness-of-fit test for model misspecification. For this reason, the previous models are extended in two directions. Firstly, we allow for transitory shocks to affect individual wages differently at different ages. This makes it possible to examine transitory and permanent wage inequality over individuals' lifecycle. Secondly, we follow the suggestion of Blundell and Preston $(1996,1998)$ and Baker and Solon (2003) and allow wage inequality to vary by cohort. These two extensions turn out to be crucial for obtaining a model that passes the test for model misspecification and obtaining consistent parameter estimates.

The outline of this paper is as follows: Section 2 discusses the data. Model selection takes place in Section 3. Section 4 presents and discusses the empirical results of the preferred model. Section 5 concludes. 


\section{The New Earnings Survey 1975-2001}

The New Earnings Survey (NES) is an annual cross-section survey of individual employees on earnings and hours of work of employees in employment in Great Britain. The employers supply the information and the data is gathered by National Statistics. All employees in employment in Great Britain who have a National Insurance (NI) number that ends with a specified pair of digits form the sample. The NI number is issued randomly to each individual over the age of 16 and the sampling frame for the Survey is a $1 \%$ random sample of all employees. Since in every year the same pair of terminating digits of the NI number is used as the basis for each year's sample, one can easily generate an unbalanced panel from the annual cross-section surveys. The panel is characterised by new cohorts entering the sample when starting employment and older cohorts exiting because of retirement. In this study the panel covers the period 1975-2001.

The sample contains information on the individual's gross weekly pay, including overtime pay, measured in April of each year. Furthermore, this study uses the information collected on the employee's hours of work, age and gender. As is most often the case with administrative data, the NES has little information on individual characteristics and no information on household characteristics. There is information on the individuals' occupational classification of the job and industrial classification of the firm at which employed. ${ }^{4}$ However, important human capital variables such as the educational attainment or work experience are not in the data.

\footnotetext{
${ }^{4}$ Prasad (2002), who also uses NES data, concludes that changes over the last two decades in the structure of employment (based on industry and occupation) did not have a dominant effect on the wage structure. Most of
} 


\subsection{Data selection}

The raw unbalanced panel consists of about half a million individuals from 1975 up to 2001 resulting in about 4.4 million observations. In line with Dickens (2000a), we exclude in the empirical analysis earnings that have been affected by sickness, absence, short-time working or employment starting within the recording period ${ }^{5}(9.4 \%$ of the observations) and earnings of multiple jobholders $(1.3 \%)$. In addition, $3.6 \%$ of the observations record a missing value for the variable that identifies an employee with multiple jobs and these are also excluded from the sample. About 7\% record a missing value on either earnings or on hours of work. As mentioned above, the Survey contains no information on individual's educational attainment or on household characteristics such as marital status or the presence of children. This makes it impossible to control for possible sample selection issues. This is in particular of importance for the female wage distribution and for this reason the empirical analysis is confined to male employees (57\%). We select men aged $21-59$ years in any year $(87 \%$ of the male employees). ${ }^{6}$ To ensure robustness of the results we exclude individuals in the top and bottom $0.1 \%$ of the wage distribution (this excludes on average 120 observations per year). The final sample used in the empirical analysis comprises on average around 66,000 men in any year, in total 1,77 million observations over 219,495 individuals from 1975 up to 2001.

the increase in the variation of (log-) earnings is due to an increase in within group wage inequality. Juhn, Murphy and Pierce (1993) report a similar finding for the U.S.

${ }^{5}$ The recording period varies from one week to one month. This information is not available. National Statistics uses this information to calculate hourly and weekly earnings, which are variables in the available NES.

${ }^{6}$ Here we deviate slightly from the selection of Dickens (2000a), using NES 1975-1995, who selects men aged 22-54 and born between 1921 and 1968. 


\subsection{Panel attrition}

The NES has not been designed for the purpose of constructing a panel and is mostly used as a series of representative cross sections by National Statistics. As mentioned above, the fact that the NI number is used to sample individuals makes it possible to construct the panel. At the stage of the data gathering process little attention is paid to the panel aspect of the survey and possible selection problems may arise from sample attrition in the NES. The discussion on this underneath is based on Dickens (2000a).

Only those who are in employment enter the sample and therefore absence from the panel can occur because individuals retire, become unemployed or inactive. Absence from the panel while being employed is a major concern for this study and can occur for two main reasons. The first is related to the way the data are gathered. Some responses are obtained directly from large public and private organizations that use their computerised administrative databases for this purpose, and these are directly contacted. ${ }^{7}$ The largest share of the employers (about 75\%) is contacted through the Inland Revenue tax register using current Pay-As-You-Earn (PAYE) records and a questionnaire is sent to complete by the employer. To be registered on the PAYE tax record the individual's earnings has to exceed a tax threshold. For example, the threshold is about 80 pounds in 1998, which is 22 hours of work at minimum wage. In the empirical investigation we use men aged 21-59 and we believe the results for this group are unlikely to be affected by this threshold. The second main reason for absence is the time in between locating the employer of the individual and when the employer receives the questionnaire. This period between the sampling and actually

\footnotetext{
${ }^{7}$ This method of tracing individuals was introduced in 1981 and initially accounted for only a small fraction of employees in the NES. However, by 1983, this method of data collection has been extended considerably so that for $25 \%$ of the employees the information is obtained directly from the employer. This proportion of $25 \%$ remained fairly constant in subsequent years (see Dickens, 2000a).
} 
data gathering can be about one month and consequently an employee may have disappeared from the employers' pay roll if this employee has changed jobs during this time. Thus employees with high rates of job turnover are likely to be under represented in the sample. Consequently, the NES may overstate the permanent component of earnings since individuals with more transitory income, unstable employment patterns, are less likely to be in the sample (see Dickens, 2000a, for more details). Obviously, this kind of attrition is endogenous in the sense that it biases the results towards a higher degree of persistency of earnings shocks. Also, since we are interested in changes over time, over time National Statistics has tried to improve her procedure to trace individuals. Hence this may as well have affected the time trend in the ratio between transitory and permanent wage inequality. This ratio may also have changed over time because an increasing number of firms having a fully computerized salary administration and returning the necessary information with relatively little effort and high accuracy. We do not have the information to control for this, if there is indeed endogenous selection, and a therefore necessary assumption made throughout the paper is that sample attrition is exogenous. Arguably, the unbalanced panel used in this study may suffer from far less endogenous selection than many of the previous U.S. studies using a balanced panel of PSID data over periods up to 20 years (for example Baker, 1997).

The advantages of using the NES need to be stressed as well. The consistency of the questionnaire over time and the ability to follow so many employees, on average 164.000 per year, for up to 27 years is unique for micro-data. The questionnaires are sent to the employers and not to the employees and the employers are under a legal obligation to complete the questionnaire (Statistics of Trade Act 1947), which ensures a high response rate. The data is provided from payroll records, giving a very high degree of accuracy in the earnings information. For instance, the variance of log-earnings based on the British Household Panel 
Study (Ramos, 2003) is about four times the variance of log-earnings based on the NES ${ }^{8}$. There might be some definitional differences but it is most likely that much of this difference is due to differences in the variances of the measurement error in earnings. Moreover, if an individual is not included in the Survey in any year, for example due to unemployment, the sampling frame ensures that the employee should be located for the Survey in any future year when in employment. Consequently, absences from the survey or failures of sample location do not lead to cumulative attrition.

\subsection{The Variance-Covariance Matrix of Log-Wages}

We follow Abowd and Card (1989), Baker and Solon (2003) and Dickens (2000a) to compute the variance-covariance matrix of the logarithm of hourly gross earnings (referred to as log-wages from here onwards). Let $y_{i b t}$ denote the log-wage of individual $i$ in year $t$ and who is born in year $b$, and let $d_{i b t}$ denote a dummy variable equal to 1 if individual $i$, born in year $b$, is present in the sample in year $t$, and 0 otherwise. We construct the variancecovariance matrix by birth-cohort. The number of individuals in the panel born in year $b$ is denoted by $n_{b}$ and $t_{b}$ denotes the length of the panel for birth-cohort $b$, i.e. the number of periods of observation. As discussed above, the sample consists of men aged 21-59 over the period 1975-2001, hence the oldest birth-cohort is 1916 and the youngest birth-cohort is 1980. The elements of the variance-covariance matrix $m_{b}$, a $\left(t_{b} \times t_{b}\right)$-matrix, for each birthcohort $b$ are computed as follows (log-wages $y_{i b k}$ is measured in deviation of its mean):

$$
m_{b}[k, l]=\frac{\left(\sum_{i=1}^{n_{b}} y_{i b k} y_{i b l}\right)}{\left(\sum_{i=1}^{n_{b}} d_{i b k} d_{i b l}\right)},
$$

\footnotetext{
${ }^{8}$ Here we used our own sample, which contains information on gross weekly pay. Details are available upon request.
} 
with $k, l=\left\{1, . ., t_{b}\right\}$ and $b=\{1916, . ., 1980\}$. The matrix $m_{b}$ is symmetric with $\frac{1}{2} t_{b}\left(t_{b}+1\right)$ distinct elements. $\operatorname{VECH}\left(m_{b}\right)$ is a $\left(\frac{1}{2} t_{b}\left(t_{b}+1\right) \times 1\right)$-vector where the $V E C H$ operator stacks the distinct elements of the $m_{b}$ matrix. The vector of moments is denoted by $m=\left(\operatorname{VECH}\left(m_{1916}\right)^{T}, . ., \operatorname{VECH}\left(m_{1980}\right)^{T}\right)^{T}$. The elements of the variance-covariance matrix of $\operatorname{VECH}\left(m_{b}\right)$, denoted by $V_{b}$, can be rewritten as follows:

$$
\operatorname{COV}\left(m_{b}[k, l], m_{b}[p, q]\right)=\frac{\sum_{i=1}^{n_{b}} d_{i b k} d_{i b l} d_{i b p} d_{i b q}}{\left(\sum_{i=1}^{n_{b}} d_{i b k} d_{i b l}\right)\left(\sum_{i=1}^{n_{b}} d_{i b p} d_{i b q}\right)}\left(m_{b}(k, l, p, q)-m_{b}(k, l) m_{b}(p, q)\right),
$$

with $m_{b}(k, l, p, q)=\frac{\sum_{i=1}^{n_{b}} y_{i b k} y_{i b l} y_{i b p} y_{i b q}}{\sum_{i=1}^{n_{b}} d_{i b k} d_{i b l} d_{i b p} d_{i b q}}$ and $k, l, p, q=\left\{1, . ., t_{b}\right\}$ and $b=\{1916, . ., 1980\}$. We denoted the variance-covariance matrix of $m$ by $V . V$ is a block diagonal matrix with on the diagonal $V_{1916}, . ., V_{1980}$.

For the oldest birth-cohort 1916 we only have one wage observation in $1975\left(t_{b}=1\right)$, for the 1917 birth-cohort we have two observations (1975 and 1976, $\left.t_{b}=2\right)$ and so forth, up to birth-cohort 1941 for which we have 26 observations $\left(1975-2000, t_{b}=26\right)$. For the birthcohorts 1942 up to and including 1954 we have 27 observations, i.e. 13 birth-cohorts we observe over the entire sample period $\left(1975-2001, t_{b}=27\right)$. For the birth-cohort of 1955 we have 26 observations $\left(t_{b}=26\right)$, and so forth, up to the youngest birth-cohort of 1980 for which we have one observation (2001, $\left.t_{b}=1\right)$. As mentioned above, for each birth-cohort we have $\frac{1}{2} t_{b}\left(t_{b}+1\right)$ distinct elements. The total number of distinct elements is denoted by $n$, 
$n=\sum_{b=1916}^{1980} \frac{1}{2} t_{b}\left(t_{b}+1\right)$, and is equal to $11466 .{ }^{9}$ Table 1 reports on the number of observations on which the elements of the variance-covariance matrix of log-wages are based. The element based on the lowest number of observations turns out to be the covariance between the logwages in 1975 and 2001 for individuals born in 1941 and is based on only 441 observations. As Table 1 shows, most distinct elements are based on more than 1000 observations.

\subsection{Descriptive Statistics}

Table 2 reports on the basic descriptive statistics for selected years. The hourly wage rate is defined as standard gross hourly earnings including overtime payments. Wages are in 2001 £s, with deflation by the Retail Price Index. The measures that we use for wage inequality are the variance of the log-wage and the ratio of the $90^{\text {th }}$ and $10^{\text {th }}$ percentile of the wage distribution. As reported in Dickens (2000a), Table 2 shows a strong increase in wage inequality over time from 1975/1980 to 1995 and hereafter wage inequality has remained fairly constant (see also Figure 2). Figure 1 shows for different year-of-birth-cohorts the increase in wage inequality by age. In contrast with Table 2, Figure 1 does not clearly show a constant wage inequality in the later years of observation, hence during the second half of the 1990's. This suggests that the stabilisation of wage inequality in the second half of the 1990's may be due to a compositional effect. The general picture that emerges from Figure 1 is that the variance of log-wages increases with age and that in particular the new entrants in the labour force appear to experience a larger variance of log-wages.

Figure 2 shows the variance-covariance structure of log-wages over time. The covariances, at all orders, show a similar time pattern as the variance. More importantly, the

\footnotetext{
${ }^{9}$ Computation: $n=2 \times \sum_{t_{b}=1}^{t_{b}=26} \frac{1}{2} t_{b}\left(t_{b}+1\right)+13 \times 27(27+1)=11466$.
} 
lines are parallel and at a rather stable equal distance over time, which may be because of a stable error structure of wages over time. As a consequence, the correlations over time are remarkable stable over time (Figure 3) although a formal test ${ }^{10}$ would reject the null hypothesis of time constant correlations. The correlation structure is remarkable similar to those reported in the U.S. literature discussed in the introduction (e.g. Abowd and Card, 1989). The correlations and covariances of log-wages decrease with the order at a decreasing rate and appear to converge to a positive level of covariance, which suggests presence of a permanent component in the variance of log-wages.

\section{Model Specification and Estimation}

Section 3.1 discusses the estimation and testing procedures. Section 3.2 reviews the different econometric models used in the literature for analysing the variance-covariance structure of wages and extends these by allowing for cohort effects.

\subsection{Model Estimation and Specification Test}

The main objective of the empirical analysis is to model the stochastic process that generates the observed variance-covariance structure of the logarithm of individuals' wage rates. The estimation procedure described underneath closely follows Abowd and Card (1989) and Dickens (2000a). We employ a Minimum Distance Estimator to fit a specific specification of the variance-covariance structure of wages, say $f(b)$, to the actual observed structure $m$, section 2.3):

\footnotetext{
${ }^{10}$ Tests have been carried out as suggested by MaCurdy (1982) to obtain a first impression of the data.
} 


$$
\hat{b}=\underset{b}{\arg \min }[m-f(b)]^{T} A[m-f(b)]
$$

where $b$ is a $(k \times 1)$-vector containing the parameters of interest, $\hat{b}$ is its Minimum Distance estimate and $A$ is an appropriate weighting matrix. Chamberlain (1984) shows that the optimal weighting matrix is $V^{1}$, where $V$ is the variance-covariance matrix of $m$ as defined in section 2.3. Altonji and Segal (1996) examine the small sample properties of the Minimum Distance Estimator. On basis of a simulation study they conclude that the Optimal Weighted Minimum Distance (OMWD) estimates suffer from a serious finite sample bias due to correlation between the sampling errors in $m$ and $V$ and strongly suggest using Equally Weighted Minimum Distance. We follow their suggestion, as do most recent empirical studies in this area, and use the Equally Weighted Minimum Distance (EWMD) estimator. In case of the EWMD estimator the weighting matrix $\mathrm{A}$ is equal to the identity matrix $\left(A=I_{n}\right)$. The variance-covariance matrix of the parameter estimates is given by:

$$
V(\hat{b})=\left(G^{T} A G\right)^{-1} G^{T} A V A G\left(G^{T} A G\right)^{-1}
$$

with $G=\frac{\partial f(b)}{\partial b}$ evaluated in $\hat{b}$.

A $\chi^{2}$ goodness of fit test is used to evaluate the performance of a specific model $f(\hat{b})$ in explaining the observed variance-covariance structure of (log-) wages. This test statistic for model misspecification is given by:

$$
(m-f(\hat{b}))^{T} R^{-}(m-f(\hat{b})) \sim \chi^{2}(n-k) .
$$

With $R=W V W^{T}$ and $W=I_{n}-G\left(G^{T} A G\right)^{-1} G^{T} A . R^{-}$is a generalised inverse of $R$. The degrees of freedom of the test is equal to the number of elements in $m$, i.e. $n=11466$, minus the number of parameters, i.e. $k$. 


\subsection{An Overview of the Empirical Models and Model Selection}

In the following we present several econometric models that have been dominating the literature on transitory and permanent wage inequality over the last two decades and assess their performance.

A popular specification of the stochastic process of log-wages is to allow for individual differences in log-wages that are assumed to be constant over time, i.e. a random individual specific effect, and an error component that is assumed to be independently distributed across individuals but is allowed to correlate over time. Following MaCurdy (1982), such a structure is formalized as follows:

$$
y_{i t}=\alpha_{i}+v_{i t},
$$

where $y_{i t}$ is the log-wage of individual $i$ in period $t$ (in deviation of its mean), $\alpha_{i}$ is a time invariant individual specific effect with mean 0 and variance $\sigma_{\alpha}^{2}$ and $v_{i t}$ is assumed to follow an $\operatorname{ARMA}(p, q)$ process. In this model the variance of the individual specific effect, $\sigma_{\alpha}^{2}$, is interpreted as permanent wage inequality and the variance of $v_{i t}$ is interpreted as transitory wage inequality. The $\operatorname{ARMA}(p, q)$ process is formalised as follows:

$$
\sum_{j=0}^{p} a_{j} v_{i t-j}=\sum_{j=0}^{q} m_{j} \varepsilon_{i t-j}
$$

where $\varepsilon_{i t}$ is assumed to be white noise, i.e. serially independently distributed error terms with mean 0 and variance $\sigma_{t}^{2}, \varepsilon_{i t} \sim i i d\left(0, \sigma_{\varepsilon, t}^{2}\right)$. The autoregressive parameters are denoted by $a_{j}$ with $a_{0}=1$ and the moving average parameters are denoted by $m_{j}$ with $m_{0}=1$. The parameters $p$ and $q$ are the orders of, respectively, the autoregressive and moving average process. If $p$ and $q$ are both zero this error component follows a pure white noise process. The $a_{j}$ and $m_{j}$ parameters are assumed constant over time. Moffitt and Gottschalk (2002) provide empirical evidence in support of this assumption. We follow MaCurdy (1982) and estimate the model 
formed by equations (1) and (2) using several specifications for the $\operatorname{ARMA}(p, q)$ structure. We choose $p$ to be equal to 1 and increase $q$ until the additional $M A$ coefficient is insignificant. To initialise the stochastic process of $v_{i t}$ we follow MaCurdy (1982, p.92/93) and assumed that the variances of the white noise $\left(\sigma_{\varepsilon, t}^{2}\right)$ for 1974 and 1975 are equal. As it turned out, an $\operatorname{ARMA}(1,4)$ structure suffices and the $a_{1}$ coefficient is in every model specification significantly different from -1 . This result rules out the so-called unit-root model suggested by Abowd and Card (1989) which would require the restriction $a_{l}=-1$ to hold.

The goodness of fit test reported in Table 3 shows that MaCurdy's (1982) model does not fit the data well. This is not a very surprising result since as is apparent from Figure 2, the variance of individual wages increases with age and this will not be captured by the model formulated by equations (1) and (2). Therefore, apart from allowing for permanent individual differences in the level of log-wages one may also allow for different growth rates in wages across individuals (Baker, 1997). Such a model is referred to as a random growth rate model and can be formalized as follows:

$$
y_{i t}=\alpha_{i}+\lambda_{i} A_{i t}+v_{i t},
$$

where $A_{i t}$ is the age of individual $i$ at time $t$ and $\lambda_{i}$ is the random growth term with mean 0 and variance $\sigma_{\lambda}^{2}$. This model is similar to the one used by Baker (1997) ${ }^{11}$ and nests the models advocated in the earlier studies of Lillard and Weiss (1978), MaCurdy (1982) and Abowd and Card (1989). Table 3 shows that the random growth model significantly improves

\footnotetext{
${ }^{11}$ The difference with Baker (1997) is that the covariance between the individual specific effect and the random growth rate is set equal to zero, i.e. $E\left[\alpha_{i} \lambda_{i}\right]=0$. Using the PSID data, Baker (1997) obtained a negative estimate of this covariance term. However, we find a positive estimate and, presumably due to this positive estimate of the covariance term, the estimated variances $\sigma_{\alpha}^{2}$ and $\sigma_{\lambda}^{2}$ turn out to be negative. For this reason we do not include the covariance in equation (3), in line with Dickens (2000a, p.40).
} 
the fit: a decrease in the $\chi^{2}$-statistics from 512051 to 212820 with just one degree of freedom less. Nevertheless, given a critical value of 11790 the $\chi^{2}$-test statistics is highly significant and, consequently, we conclude that the random growth model is rejected by the data. Baker (1997) reports also highly significant $\chi^{2}$-test statistics, which casts some doubt on his empirical results.

Gottschalk and Moffitt (1994) discuss the idea that returns to human capital may have changed over time as a result of permanent shocks. The 1970's oil shocks and skill biased technological change in the 1980's and 1990's are examples of causes of permanent shocks to individuals' earnings. This idea is formalised a follows:

$$
y_{i t}=p_{t}\left(\alpha_{i}+\lambda_{i} A_{i t}\right)+v_{i t} \text {. }
$$

The first part in parentheses at the right hand side of equation (4) is often referred to as the permanent component, say the accumulated human capital, and the $p_{t}$ 's are the returns to these investments. The value of $p_{t}$ in 1975 is normalised to 1 . The second part at the right hand side of equation (4) is the transitory component of earnings. An increase in $p_{t}$ causes a wider spread of the wage distribution but does not affect the ranking of individuals. In this model identification of the $p_{t}$ 's is achieved by using the covariances of log-wages over time. Without any change in the variance of the transitory wage component, an increase in $p_{t}$ decreases wage mobility, as discussed in the introduction. As it turns out, the model does not sufficiently explain the variance-covariance structure of log-wages over the observation period. As shown in Table 3, the corresponding $\chi^{2}$-test statistics is highly significant and we have to conclude that also this model is rejected by the data. Results not shown here (but available upon request) indicate that based on equation (4) the increase in permanent wage inequality is severely underestimated when compared with the increase obtained from the final model (underneath). Baker and Solon (2003) report a similar finding. 
Topel and Ward (1992) find that most wage innovations happen early in the career. A single random growth term may not capture this accurately ${ }^{12}$ and for this reason Dickens (2000a) further builds on the model proposed by Gottschalk and Moffitt (1994) and allows the earnings growth rates to vary with age, i.e. earnings are assumed the have a random walk in age. ${ }^{13}$. Dickens' (2000a) model is nested in the following one:

$$
y_{i t}=p_{t} \mu_{i a}+v_{i t},
$$

with the random walk being specified as follows:

$$
\mu_{i a}=\mu_{i a-1}+\eta_{i a}, \mu_{i 21}=\alpha_{i}, \eta_{i a} \sim i i d\left(0, \sigma_{\eta, a}^{2}\right) \text { if } \quad a>21 .
$$

As before, $\alpha_{i}$ is a time invariant individual specific effect with mean 0 and variance $\sigma_{\alpha}^{2}$. This specification allows for age specific innovations and results in an increase in the variance of the permanent earnings component with age in an arbitrary way, hence relaxes the linear function in age of the random growth model (equation (3) or (4)). Table 3 shows that this model performs reasonably well but the model is still rejected by the data. The improvement in the $\chi^{2}$-statistics is significant: a decrease from 200745 to 23316 with only 37 degrees of freedom less. This remarkable improvement in the goodness of fit strongly underlines the importance of allowing for age specific permanent shocks.

The original model proposed by Dickens (2000a), who uses the NES data up to 1995, imposes some restrictions on this model: (i) an $A R M A(1,2)$ structure instead of an $A R M A(1,4)$ structure, (ii) age-specific variances, $\eta_{i a}$, are set equal to 0 at ages over 40 , (iii) $\sigma_{\alpha}^{2}$ is set equal to zero at the youngest age (age 22 in Dickens', 2000a, model). A joint test of these restrictions yields a rejection of these restrictions by the data and we therefore do not impose

\footnotetext{
12 Baker (1997, Appendix) experiments with Age squared and he finds that this extension only marginally improves the fit of the model and concludes that a linear approximation is sufficient.

${ }^{13}$ This model is very close to the model proposed in Moffitt and Gottschalk (1995, 2002).
} 
them on the model. The restriction (iii) is, however, not rejected by the data. ${ }^{14}$ Concerning the goodness of fit test, Dickens (2000a, Table 2, p.38) reports a highly significant $\chi^{2}$-test statistic equal to 15196 with 7105 degrees of freedom (the critical value is equal to 7391 ), which already suggests some sort of misspecification of his model.

The model as formulated in equations (5) and (6) is extended in two directions. Firstly, the transitory shocks in wages are allowed to differ with age. One important reason for allowing for this extension is that one may expect higher wage mobility earlier in an individual's career (Topel and Ward, 1992) and once a career is consolidated wages are less affected by transitory wage shocks. This is formalised as follows:

$$
\begin{aligned}
& y_{i t}=p_{t} \mu_{i a}+q_{a} v_{i t}, \\
& \mu_{i a}=\mu_{i a-1}+\eta_{i a}, \mu_{i 21}=\alpha_{i}, \eta_{i a} \sim i i d\left(0, \sigma_{\eta, a}^{2}\right) \text { if } a>21 .
\end{aligned}
$$

The age specific parameter $q_{a}$ scales the impact of transitory shocks and is normalised to 1 at age 21 , i.e. $q_{21}=1$. This model allows not only the variance of the permanent wage component to increase with age but also allows changes in the variance of the transitory wage component, hence provides more insights in how wage inequality and mobility changes with age. This model is referred to as the Year-Age model and Table 3 shows that the fit is improved significantly, suggesting that transitory shock do impact differently the wages of individuals at different ages. However, this extension is not sufficient for obtaining a model that passes the goodness of fit test.

\footnotetext{
${ }^{14}$ A (minor) difference between Dickens (2000a) and the model as outlined in equations (5) and (6) is that Dickens (2000a) formulates equation (5) as follows: $y_{i t}=p_{t} \mu_{i a}+\delta_{t} v_{i t}$, with $v_{i t}$ following an ARMA(p,q) process as in equation (2) but with $\varepsilon_{t} \sim i i d\left(0, \sigma_{\varepsilon}^{2}\right)$, i.e. a constant variance over time. Ramos (2003) models this part of the transitory component the same way we do.
} 
As discussed in the introduction, Blundell and Preston $(1996,1998)$ show the significance of cohort effects in the permanent variance of income: cohort entering the labour market in the late 1980's face significantly higher permanent income inequality compared to the older cohorts. ${ }^{15}$ Similarly, Ramos (2003) concludes there is lower earnings mobility for the younger cohorts during the 1990's. For this reason we extend the model as formulated above by allowing for cohort effects in the permanent and transitory variances of log-wages:

$$
\begin{aligned}
& y_{i t}=p_{t} r_{c} \mu_{i a}+q_{a} s_{c} v_{i t}, \\
& \mu_{i a}=\mu_{i a-1}+\eta_{i a}, \mu_{i 21}=\alpha_{i}, \eta_{i a} \sim i i d\left(0, \sigma_{\eta, a}^{2}\right) \text { if } a>21 .
\end{aligned}
$$

This model is referred to as the Year-Age-Cohort model. The advantage of modelling cohort effects in this multiplicative way is that it allows a cohort to have either a different return to the permanent component of wages $\left(p_{t}\right)$ or a different variation in the permanent component $\left(\mu_{i a}\right)$, say because of differences in the skill dispersion between cohorts. ${ }^{16}$

Including cohort effects in this non-parametric way in both the permanent and transitory component of log-wages yields an unidentified model. The reason for this is that we have only one moment condition for men born in 1916 who are aged 59 in 1975 and one for men born in 1980 who are aged 21 in 2001 and this makes it impossible to identify both the transitory and permanent variances of log-wages for these cohorts. In theory, normalising $r_{c}$ and $s_{c}$ to be equal to 1 for the 1916 and 1917 birth-cohorts and equalising $r_{c}$ 's and $s_{c}$ 's for the 1979 and 1980 birth-cohorts yields an identified model. In practice, however, we experienced several poorly determined cohort effects when trying to estimate all theoretically

\footnotetext{
${ }^{15}$ Several studies have examined cohort effects on wages and returns to schooling and experience (Welsh, 1979, Behrman and Birdall, 1988). For instance, Welsh (1979) examines the effects of cohort size on wages and find significant effects - with differences in the effects across education groups - and also shows that cohort effects decline over the career, suggesting that part of the cohort effects are transient.

${ }^{16}$ From another perspective: we cannot separately identify these two different cohort effects.
} 
identified parameters. ${ }^{17}$ For this reason we normalise $r_{c}$ and $s_{c}$ to be equal to 1 for the birthcohorts of 1916-1924, hence the cohorts entering employment before 1946, and equalise the $r_{c}$ 's and $s_{c}$ 's for the birth-cohorts of 1978-1980, hence the cohorts entering employment after 1998.

Table 3 shows that the Year-Age-Cohort model passes the goodness of fit test, the improvement is significant suggesting that cohort effects are of major importance explaining the variance-covariance structure of log-wages. This will be investigated in detail in the next section. Baker and Solon (2003), using Canadian administrative data, estimate a model that is conceptually quite similar to ours but do not report a goodness of fit test statistic for their model. ${ }^{18}$ In line with our results, they do conclude that including cohort effects significantly improves the fit of the model explaining the variance-covariance structure of wages and furthermore they conclude that omitting cohort effects leads to misleading results concerning the changes in the variances of the permanent and transitory wage component. This latter issue will be investigated in the next section. Ramos (2003) estimates a model that is more restrictive than the Year-Age-Cohort model. Apart from making additional assumptions on the random walk process in equation (10), in line with Baker (1997), and the birth-cohort effects, his model does not allow the transitory shocks to differ with age. As we will show in the next section, this latter restriction turns out to be of crucial importance.

\footnotetext{
${ }^{17}$ To be more precise: the standards errors corresponding to some of the cohort effects became relatively large with parameter estimates remaining close to 1 .

${ }^{18}$ Baker and Solon (2003) model cohort effects differently: they allow the variances $\sigma_{\alpha}^{2}$ and $\sigma_{\lambda}^{2}$, i.e. the variance of the random growth term of wages, and the initial transitory variance to differ by cohort. They do impose some functional forms such as restricting the variance of the transitory component to a polynomial in age. Our model is more flexible, in the sense of using a fully non-parametric specification.
} 


\section{4 . Empirical Results}

The Year-Age-Cohort model as formulated in equations (9) and (10) with an $\operatorname{ARMA}(1,4)$ specification for the stochastic process of $v_{i t}$ is our preferred specification to analyse the changes in the variance-covariance structure of (log-) wages over time and individuals' lifecycle, hereby controlling for cohort effects in both permanent and transitory wage inequality. For the purpose of gaining insights in parameter estimates, we will plot the year, age and cohort profiles of the variance of (log-) wages and its permanent and transitory components, and we refer for the individual parameter estimates to Table 4.

Before proceeding to the discussion of the results we like to make two remarks. Table 4 shows that a few of the age-specific variances of the random walk are estimated to be negative. These negative estimates are all insignificant and setting them equal to 0 does not change any of the results discussed underneath. ${ }^{19}$ The interpretation of the results before 1979 demands caution because MaCurdy's $\operatorname{ARMA}(p, q)$ representation of the stochastic process is only a valid representation of the stochastic process of $v_{i t}$ after $q$ periods (MaCurdy, 1982, p.93). For example, the estimates of $\sigma_{\varepsilon, t}^{2}$ in 1975 and 1976 are relatively large and this may solely be the effect of the "start-up" of the stochastic process and will depend on the way one initialises the stochastic process (see section 3.1). For this reason we prefer to restrict the discussion of the results to the years from 1980 onwards.

\footnotetext{
${ }^{19}$ Dickens (2000a) sets $\sigma_{\alpha}^{2}$ equal to zero at the youngest age for a similar reason (age 22 in his case).
} 


\subsection{Estimation Results of the Year-Age -Cohort Model}

Figure 4 shows the estimated variances of the transitory and permanent wage component over the period 1975-2001, keeping age and cohort constant (i.e. age is set equal to 40 and $r_{b}$ and $s_{b}$ are set equal to 1$)$. The most striking feature of Figure 4 is that the increases in wage inequality over the observation period is mainly due to an increases in transitory wage inequality and only to lesser extent due to an increase in permanent wage inequality. This result is in line with the findings of Ramos (2003) and Blundell and Preston (1998, Figure V). This latter study shows a widening cap between the variances of household income and consumption from the early 1980's onwards, which suggests a relatively stronger increase in transitory than permanent income inequality. This result is, however, in sharp contrast to the findings in Dickens (2000a) who concludes an equal rise in the permanent and transitory component of the variance of log-wage. We return to this contrasting finding in section 4.2.

Permanent wage inequality has increased during the 1980's and has slightly decreased during the second half of the 1990's. Nevertheless, the strong increase in transitory wage inequality results in a continuation of the rise in wage inequality throughout the 1990's. This is in contrast to suggestions of the raw statistics shown in Table 2 and Figure 2 and underlines the importance of controlling for age and cohort effects. The increase in overall wage inequality has diminished in the second half of the 1990's, as a result of the decrease in permanent wage inequality, but has again increased in 2001. The estimation results in Table 4 show that the variance of the transitory wage shock $\left(\sigma_{\varepsilon, t}^{2}\right)$ has remained fairly constant since 1995. This caused a slowdown in the increase in transitory wage inequality. The direct effect is limited because of the high degree of persistency in the transitory component of wages, as will be discussed below (Figure 7), but if remaining constant it will eventually lead to constant transitory wage inequality. 
As discussed in the introduction, wage mobility is affected by changes in both the variances of the transitory and permanent component of log-wages (Moffitt and Gottschalk, 1995). To assess changes in wage mobility Figure 5 plots the ratio of the variances of permanent and transitory log-wage components; perhaps better referred to as wage immobility. Figure 5 shows a decline in this ratio over the observation period, which suggests an increase in wage mobility. In other words, although there has been an increase in permanent wage inequality over the observation period the probability of individuals changing ranks within the wage distribution has also increased during this period. In this respect we reach an opposite conclusion from Dickens' (2000b). He concludes a decrease in wage mobility. ${ }^{20}$ Based on the results of Dickens (2000a) that transitory and permanent wage inequality rise at the same rate, one may conclude that wage mobility remained fairly constant from 1975 to 1995 . We return to this finding in section 4.3. Ramos (2003) concludes, in line with our results, that wage mobility in Britain has increased during the 1990’s.

To assess lifecycle inequality Figure 6 shows the variances of the transitory and permanent wage component over individuals' lifecycle. For this purpose the year is set equal to 1990 and $r_{b}$ and $s_{b}$ are set equal to 1 . Figure 6 shows that wage inequality increases over individuals' lifecycle up to age 50 and decreases from there on. A dominating feature of Figure 6 is the strong increase in permanent wage inequality up to age 36 and the relatively constant permanent wage inequality from there on a up to age 50. This finding is in line with Topel and Ward (1992) who find that most wage innovations happen early in the career. The results in Figure 6 also imply that wage mobility decreases dramatically with age up to age 30 , remaining constant from age 30 to age 36 , increases with age from age 36 up to age 50 , and decreases with age after age 50. Furthermore it is noteworthy that the patterns over the

\footnotetext{
${ }^{20}$ This may be caused by the fact he uses a mobility index without controlling for age and cohort effects.
} 
lifecycle suggest that allowing variances to be a linear or quadratic function of age, as is sometimes suggested in the literature (Baker and Solon, 2003), may not be sufficient. Our findings in Figure 6 are in sharp contrast with Ramos (2003) who concludes that relative earnings persistence declines over the lifecycle. His result may be driven by the fact his model does not allow the transitory shocks to differ with age. In section 4.2 we discuss the consequences of this restriction.

Figure 7 plots the permanent and transitory log-wage components for the different cohorts, i.e. at the year of turning 21 . For this purpose age is set equal to 40 and the year is set equal to 1990. The most striking feature of Figure 7 is the rise in wage inequality for the cohorts entering employment during the 1980's and the decrease in wage inequality for cohorts entering during the 1990's. These changes are mainly due to changes in transitory wage inequality. Blundell and Preston (1998) conclude that the late 1980's cohorts experience higher permanent income inequality. Apart from an increase in permanent wage inequality for the 1989 cohort we find little support for extending their findings to wage inequality. Figure 7 shows that transitory wage inequality decreases with the cohort for cohorts entering employment during the 1990's, which in combination with relatively constant permanent wage inequality implies lower wage mobility for the younger cohorts.

Figure 8 plots the estimated correlation coefficient between two periods of the transitory wage component. The correlation coefficient is about 0.88 over one period and only very gradually decreases from there on, and is still 0.65 over a 10 year period and 0.30 over a 40 year period. This high degree of persistency is also found in Dickens (2000a). Using the income variable from the British Household Panel Survey, Jarvis and Jenkins (1998) reports somewhat lower "raw" correlation coefficients. A consequence of this high degree of persistency is that permanent wage inequality based on individuals' lifetime 
earnings will be larger than when based on within period permanent wage inequality. ${ }^{21}$ The sharp increase in transitory wage inequality as shown in Figure 4 will therefore have, from an individual's lifecycle perspective, long-term effects.

\subsection{The empirical importance of controlling for cohort effects and age-specific transitory wage inequality}

Section 3 argued, based on the goodness of fit test statistic, that controlling for cohort effects is of empirical importance. To assess the empirical importance we compare the main results with the results obtained from a model without controlling for cohort effects, i.e. equations (7) and (8). These comparisons are graphed in Figures 9 and 10. Ignoring cohort effects yields an underestimation of the rise over the years in transitory wage inequality and, consequently, an overestimation of the rise in permanent wage inequality (Figure 9). The same conclusion can be drawn when comparing lifecycle wage inequality: especially between the age of 36 and 50 permanent wage inequality is overestimated (Figure 10). However, ignoring cohort effects cannot fully explain the difference between our results and those of Dickens (2000a), as discussed in section 4.1. Dickens (2000a) also does not allow the transitory wage inequality to differ with age and we therefore also impose this restriction on our model, hence estimate equations (5) and (6) and plot the predicted wage inequality over time in Figure 11. Figure 11 shows that, in line Dickens (2000a), we would conclude that there has been an almost equal increase in the transitory and permanent wage inequality from 1975 to 1995 when ignoring that transitory wage inequality differs with age. In other words, Dickens (2000a) severely overestimates the rise in permanent wage inequality and underestimates the rise in transitory wage inequality. Figure 12 shows more explicitly the

\footnotetext{
${ }^{21}$ Only in the case of no serial correlation there would be no difference.
} 
assumption made by Dickens (2000a), Ramos (2003) and studies using U.S. data, of an ageinvariant transitory component (the horizontal line).

\section{Summary and Conclusions}

We examine the changes in the variances of the transitory and permanent components of the logarithm of gross hourly wages of British men over the years 1975-2001 and disentangle the year, age and cohort effects on the variance components. For this purpose we use the New Earnings Survey. Previous econometric models developed in the literature for analysing the variance-covariance structure of wages (MaCurdy, 1982, Baker, 1997, Gottschalk and Moffitt, 1994, Dickens, 2000a, Moffitt and Gottschalk, 2002) do not pass a test for model misspecification. We therefore extend these models and allow transitory shocks to affect individual wages differently at different ages and, following the suggestion of Blundell and Preston (1996, 1998), Ramos (2003) and Baker and Solon (2003), by allowing wage inequality to vary by cohort. These two extensions turned out to be crucial for obtaining a model that passes the test for model misspecification and obtaining consistent parameter estimates. Ignoring these two extensions are shown to yield misleading inferences of the changes in the variances of the transitory and permanent components of the log- wages.

Descriptive statistics show that wage inequality for British men has risen sharply during the 1980's and early 1990's and has remained constant in the second half of the 1990's. The empirical analysis provide the following main insights in these trends:

(i) The increase in wage inequality from the early 1980's onwards is caused mainly by a strong increase in transitory wage inequality and only to a lesser extent by an increase in the permanent wage inequality. 
(ii) The increase in transitory wage inequality continued to increase up to 2001 . The increase in permanent wage inequality took place in the second half of the 1980 's and the first half of the 1990's and even decreased in the second half of the 1990's.

(iii) The transitory component of wages is highly persistent over time: serial correlation decreases from 0.88 over a one-year period to 0.65 over a ten-year period. Hence, the increase in transitory wage inequality has persistent inequality consequences from an individual's lifecycle perspective.

(iv) A strong decrease in the transitory wage inequality of the new cohorts entering employment since the end of the 1980's. Permanent wage inequality varies relatively little across cohorts.

\section{References}

Abowd, J.M. and Card, D. (1989): On the Covariance Structure of Earnings and Hours Changes, Econometrica, Vol.57, 2, 411-445.

Acemoglu, D. (2002): Cross country inequality trends, Working Paper Series, No. 02-14, Department of economics, Massachusetts Institute of Technology.

Altonji, J.G., and Segal, L.M. (1996): Small-Sample Bias in GMM Estimation of Covariance Structures, Journal of Business \& Economic Statistics, Vol. 14, No. 3, 353-366.

Attanasio, O., Berloffa, G., Blundell, R., and Preston, I. (2002): From earnings inequality to consumption inequality, The Economic Journal, 112, C52-C59. 
Atkinson, A.B., Bourguignon, F., and Morrisson, C. (1992): Empirical Studies of Earnings Mobility, Reading: Harwood Academic Publishers.

Baker, M. (1997): Growth-Rate Heterogeneity and the covariance Structure of Life-Cycle Earnings, Journal of Labor Economics, vol.15, no.2, 338-375.

Baker, M, and Solon, G. (2003), "Earnings Dynamics and Inequality among Canadian Men, 1976-1992: Evidence from Longitudinal Income Tax Records”, Journal of Labor Economics, forthcoming.

Behrman, J.R., and Birdsall, N. (1988): "The Reward for Good Timing: Cohort Effects and Earnings Functions for Brazilian Males", The Review of Economics and Statistics, Vol.70, Issue 1, 129-135.

Blundell, R. and Preston, I. (1996): Income, Expenditure and the Living Standards of UK Households, Fiscal Studies, Vol.16, 3, 40-54.

Blundell, R. and Preston, I. (1998): Consumption inequality and income uncertainty, The Quarterly Journal of Economics, 603-640.

Buchinsky, M. and Hunt, J. (1999): Wage Mobility in the United States, The Review of Economics and Statistics, 81 (3), 351-368.

Cappellari, L. (2003): The Dynamics and Inequality of Italian Men's Earnings: Long-term Changes or Transitory Fluctuations?, Journal of Human Resources, forthcoming.

Chamberlain, G, (1984): Panel Data, Handbook of Econometrics, Eds. Grilliches, Z., and Intrilligator, M., Amsterdam: North-Holland, 1247-1318.

Dickens, R. (2000a): The evolution of individual male earnings in Great Britain: 1975-1995, The Economic Journal, 110, 27-49.

Dickens, R. (2000b): Caught in a Trap? Wage Mobility in Great Britain: 1975-1994, Economica, 67, 477-497. 
Gosling, A., and Lemieux, T. (2001): Labour market reforms and changes in wage inequality in the United Kingdom and the United States, Working Paper 8413, National Bureau of Economic Research.

Gosling, A., Machin, S., and Meghir, C. (2000): The Changing Distribution of Male Wages in the UK, The Review of Economic Studies, Vol.67 (4), 635-666.

Gottschalk, P., 1982: Earnings mobility: permanent change or transitory fluctuations?, The Review of Economics and Statistics, 64, 450-456.

Gottschalk, P. and Moffitt, R. (1994): The growth on earnings instability in the US labor market, Brookings Papers on Economic Activity, no.2, 217-272.

Gottschalk, P. and Joyce, M. (1998): Cross-national differences in the rise in earnings inequality: market and institutional factors, Review of Economics and Statistics, 80, 489-502.

Gottschalk, P. and Smeeding, T.M. (1997): Cross-national Comparisons of Earnings and Income Inequality, Journal of Economic Literature, Vol.35, 633-687.

Jarvis, S. and Jenkins, S.P. (1998): How Much Income Mobility is there in Britain?, The Economic Journal, 108, 428-443.

Juhn, C., Murphy, K.M., and Pierce, B. (1993): Wage Inequality and the Rise in the Returns to Skill, The Journal of Political Economy, Vol.101, no.3, 410-442,

Katz, L. and Autor, D. (2000): Changes in the Wage Structure and Earnings Inequality, Chapter 26, in O. Ashenfelter and D, Card, eds., The Handbook of Labor Economics Volume III, Amsterdam: Elsevier.

Lillard, L.A. and Weiss, Y. (1979): Components of variation in panel earnings data: American scientists 1960-70, Econometrica, Vo.47, No.2, 437-454.

Lillard, L.A. and Willis, R.J. (1978): Dynamic aspects of earnings mobility, Econometrica, Vol.46, No.5, 985-1012. 
MaCurdy, T. (1982): The use of time series processes to model the error structure of earnings in a longitudinal data analysis, Journal of Econometrics, 18, 83-114.

Moffitt, R.A., and Gottschalk, P. (1995): Trends in the Autocovariance Structure of Earnings in the U.S.: 1969-1987, Working Paper, Department of Economics, Brown University.

Moffitt, R.A., and Gottschalk, P. (2002): Trends in the Transitory Variance of Earnings in the U.S., The Economic Journal, 112, C68-C73.

Prasad, E. (2002): Wage Inequality in the United Kingdom, 1975-2001, IZA Discussion Paper, No.510, Institute for the Study of Labor, Bonn.

Ramos, X. (2003): The Covariance Structure of Earnings in Great Britain, 1991-1999, Economica, 70, 353-374.

Sloane, P.J., and Theodossiou, I. (1996): Earnings mobility, family income and low pay, The Economic Journal, Vo. 106, no. 463, 657-666.

Snower, D. (1999): Causes of Changing Earnings Inequality, Discussion Paper No.29, The Institute for the Study of Labor.

Topel, R.H., and Ward, M.P. (1992): Job Mobility and the Careers of Young Men, The Quarterly Journal of Economics, 107, 439-480.

Welch, F. (1979): "Effects of Cohort Size on Earnings: The Baby Boom Babies' Financial Bust", The Journal of Political Economy, Vol.87, Issue 5, Part 2: Education and Income Distribution, S65-S97. 
Table 1: The frequency distribution of the number individual observations on which the distinct elements of the variance-covariance matrix of log-wages is based.

\begin{tabular}{llllll}
\hline Number of Observations & $<500$ & $500-1000$ & $1000-1500$ & $1500-2000$ & $\geq 2000$ \\
\hline Number of distinct elements & 53 & 3562 & 6763 & 960 & 128 \\
Percentage of distinct elements & $0.5 \%$ & $31.1 \%$ & $59.0 \%$ & $8.4 \%$ & $1.1 \%$ \\
\hline
\end{tabular}

Table 2: Number of Observations and Descriptive Statistics for Selective Years.

\begin{tabular}{lllllll}
\hline & 1975 & 1980 & 1985 & 1990 & 1995 & 2000 \\
\hline $\begin{array}{l}\text { Number of Observations } \\
\text { Average Age }\end{array}$ & 66355 & 69472 & 62464 & 66254 & 66229 & 62433 \\
& 39.8 & 39.6 & 38.8 & 38.5 & 38.5 & 39.5 \\
Hourly Wage Rate (2001£) & & & & & & \\
Average & 7.78 & 7.91 & 8.80 & 10.0 & 10.8 & 11.7 \\
Standard deviation & 3.28 & 3.45 & 4.38 & 5.75 & 6.98 & 7.8 \\
Percentiles & & & & & & \\
$5 \%$ & 4.43 & 4.34 & 4.35 & 4.54 & 4.36 & 4.74 \\
$10 \%$ & 4.88 & 4.80 & 4.89 & 5.15 & 5.05 & 5.42 \\
$50 \%$ & 6.96 & 7.02 & 7.65 & 8.45 & 8.92 & 9.56 \\
$90 \%$ & 11.6 & 12.0 & 14.0 & 16.5 & 18.4 & 19.9 \\
$95 \%$ & 14.2 & 14.6 & 17.1 & 20.5 & 23.0 & 25.4 \\
& & & & & & \\
$90^{\text {th }} / 10^{\text {th }}$ deciles & 2.38 & 2.50 & 2.86 & 3.00 & 3.64 & 3.67 \\
& & & & & & \\
Variance of log-wage & 0.12 & 0.13 & 0.16 & 0.20 & 0.25 & 0.24 \\
Average log-wage & 1.98 & 1.99 & 2.08 & 2.18 & 2.23 & 2.31 \\
\hline
\end{tabular}


Table 3: Model Selection.

\begin{tabular}{|c|c|c|c|}
\hline & Model Specification & $\begin{array}{l}\chi^{2} \text {-Test } \\
\text { (d.f.) }\end{array}$ & $\begin{array}{l}\text { Critical Value } \\
(1 \% \text { significance level) }\end{array}$ \\
\hline MaCurdy (1982) & Equation (1) & $\begin{array}{l}512051 \\
(11433)\end{array}$ & 11790 \\
\hline Baker (1997) & Equation (3) & $\begin{array}{l}212820 \\
(11432)\end{array}$ & 11790 \\
\hline Gottschalk and Moffitt (1994) & Equation (4) & $\begin{array}{l}200745 \\
(11406)\end{array}$ & 11769 \\
\hline $\begin{array}{l}\text { Dickens (2000a), } \\
\text { Extended Version }\end{array}$ & Equations (5) \& (6) & $\begin{array}{l}23316 \\
(11369)\end{array}$ & 11713 \\
\hline Year-Age Model & Equations (7) \& (8) & $\begin{array}{l}18392 \\
(11331)\end{array}$ & 11676 \\
\hline Year-Age-Cohort Model & Equations (9) \& (10) & $\begin{array}{l}10740 \\
(11271)\end{array}$ & 11628 \\
\hline
\end{tabular}

Legend: The estimation results of each model are available from the authors upon request. The estimation results of the last model, the Year-Age-Cohort-model, are reported in Table 4. An ARMA(1,4) structure is used in all models. The $\chi^{2}$-test statistics are calculated using the optimal weighting matrix, i.e. we use $V^{1}$ as the generalised inverse of $R$ (see Section 3.1), and the EWMD-estimates. 
Table 4: Estimation Results of the Year-Age-Cohort Model, equations (9) and (10) (EWMD-estimates).

\begin{tabular}{|c|c|c|c|c|c|}
\hline \multicolumn{6}{|c|}{ Year Effects } \\
\hline \multicolumn{3}{|c|}{ Permanent Component } & \multicolumn{3}{|c|}{ Transitory Component } \\
\hline Parameter & p.e. & s.e. & $\begin{array}{l}\text { Parameter } \\
\sigma_{\varepsilon, t}^{2}\end{array}$ & p.e. & s.e. \\
\hline 1975 & 1.000 & - & 1975 & 0.037 & 0.010 \\
\hline 1976 & 0.954 & 0.010 & 1976 & 0.042 & 0.013 \\
\hline 1977 & 0.915 & 0.010 & 1977 & 0.028 & 0.009 \\
\hline 1978 & 0.915 & 0.010 & 1978 & 0.026 & 0.008 \\
\hline 1979 & 0.866 & 0.009 & 1979 & 0.027 & 0.009 \\
\hline 1980 & 0.892 & 0.010 & 1980 & 0.026 & 0.009 \\
\hline 1981 & 0.988 & 0.011 & 1981 & 0.027 & 0.009 \\
\hline 1982 & 1.000 & 0.012 & 1982 & 0.023 & 0.008 \\
\hline 1983 & 0.995 & 0.012 & 1983 & 0.026 & 0.009 \\
\hline 1984 & 0.999 & 0.012 & 1984 & 0.026 & 0.010 \\
\hline 1985 & 0.992 & 0.012 & 1985 & 0.024 & 0.009 \\
\hline 1986 & 1.015 & 0.013 & 1986 & 0.025 & 0.010 \\
\hline 1987 & 1.056 & 0.014 & 1987 & 0.027 & 0.011 \\
\hline 1988 & 1.068 & 0.015 & 1988 & 0.033 & 0.013 \\
\hline 1989 & 1.088 & 0.016 & 1989 & 0.033 & 0.014 \\
\hline 1990 & 1.077 & 0.016 & 1990 & 0.034 & 0.015 \\
\hline 1991 & 1.097 & 0.017 & 1991 & 0.037 & 0.016 \\
\hline 1992 & 1.111 & 0.018 & 1992 & 0.035 & 0.016 \\
\hline 1993 & 1.132 & 0.019 & 1993 & 0.035 & 0.016 \\
\hline 1994 & 1.127 & 0.019 & 1994 & 0.037 & 0.017 \\
\hline 1995 & 1.142 & 0.020 & 1995 & 0.045 & 0.022 \\
\hline 1996 & 1.125 & 0.020 & 1996 & 0.045 & 0.022 \\
\hline 1997 & 1.094 & 0.019 & 1997 & 0.043 & 0.021 \\
\hline 1998 & 1.096 & 0.020 & 1998 & 0.045 & 0.023 \\
\hline 1999 & 1.084 & 0.020 & 1999 & 0.043 & 0.022 \\
\hline 2000 & 1.071 & 0.020 & 2000 & 0.042 & 0.022 \\
\hline 2001 & 1.114 & 0.022 & 2001 & 0.044 & 0.024 \\
\hline & & & $a_{1}$ & -0.975 & 0.005 \\
\hline & & & $m_{1}$ & -0.464 & 0.012 \\
\hline & & & $m_{2}$ & -0.041 & 0.014 \\
\hline & & & $m_{3}$ & -0.031 & 0.015 \\
\hline & & & $m_{4}$ & 0.016 & 0.010 \\
\hline
\end{tabular}

\section{Age Effects}

\begin{tabular}{lrlllll}
\multicolumn{2}{l}{ Permanent } & \multicolumn{3}{l}{ Component } & & \multicolumn{3}{l}{ Transitory Component } \\
Parameter & p.e. & s.e. & & Parameter & p.e. & s.e. \\
$\sigma_{\mu, a}^{2}$ & & & & & & \\
$21, \sigma_{\alpha}^{2}$ & -0.003 & 0.001 & 21 & 1.000 & - \\
22 & 0.012 & 0.001 & 22 & 0.928 & 0.010 \\
23 & 0.010 & 0.001 & 23 & 0.907 & 0.013 \\
\hline
\end{tabular}




\begin{tabular}{lrllll}
\hline 24 & 0.008 & 0.001 & 24 & 0.938 & 0.017 \\
25 & 0.013 & 0.001 & 25 & 0.874 & 0.020 \\
26 & 0.007 & 0.001 & 26 & 0.865 & 0.024 \\
27 & 0.007 & 0.001 & 27 & 0.872 & 0.028 \\
28 & 0.007 & 0.001 & 28 & 0.863 & 0.032 \\
29 & 0.005 & 0.001 & 29 & 0.880 & 0.036 \\
30 & 0.005 & 0.001 & 30 & 0.888 & 0.041 \\
31 & 0.003 & 0.001 & 31 & 0.903 & 0.046 \\
32 & 0.003 & 0.001 & 32 & 0.928 & 0.051 \\
33 & 0.004 & 0.001 & 33 & 0.938 & 0.056 \\
34 & 0.002 & 0.001 & 34 & 0.959 & 0.062 \\
35 & 0.002 & 0.001 & 35 & 0.981 & 0.067 \\
36 & 0.003 & 0.001 & 36 & 0.968 & 0.071 \\
37 & 0.000 & 0.001 & 37 & 1.011 & 0.079 \\
38 & 0.001 & 0.001 & 38 & 1.030 & 0.085 \\
39 & 0.000 & 0.001 & 39 & 1.052 & 0.091 \\
40 & -0.001 & 0.001 & 40 & 1.077 & 0.098 \\
41 & -0.001 & 0.001 & 41 & 1.078 & 0.103 \\
42 & 0.000 & 0.001 & 42 & 1.105 & 0.111 \\
43 & 0.000 & 0.001 & 43 & 1.093 & 0.115 \\
44 & -0.002 & 0.001 & 44 & 1.130 & 0.124 \\
45 & 0.000 & 0.001 & 45 & 1.132 & 0.129 \\
46 & -0.001 & 0.001 & 46 & 1.139 & 0.135 \\
47 & 0.001 & 0.001 & 47 & 1.141 & 0.141 \\
48 & 0.000 & 0.001 & 48 & 1.149 & 0.147 \\
49 & -0.002 & 0.001 & 49 & 1.179 & 0.156 \\
50 & 0.003 & 0.001 & 50 & 1.169 & 0.161 \\
51 & 0.000 & 0.001 & 51 & 1.161 & 0.165 \\
52 & 0.003 & 0.001 & 52 & 1.141 & 0.168 \\
53 & 0.003 & 0.001 & 53 & 1.114 & 0.169 \\
54 & 0.001 & 0.001 & 54 & 1.138 & 0.178 \\
55 & 0.005 & 0.002 & 55 & 1.053 & 0.171 \\
56 & 0.007 & 0.002 & 56 & 1.022 & 0.171 \\
57 & 0.010 & 0.002 & 57 & 0.910 & 0.159 \\
58 & 0.006 & 0.002 & 58 & 0.874 & 0.158 \\
59 & 0.017 & 0.003 & 59 & 0.725 & 0.139
\end{tabular}

Cohort Effects (year of birth)

Permanent Component

Parameter p.e. s.e.

$r_{c}$

1916-1924 $1.000 \quad-$

$\begin{array}{lll}1925 & 1.032 & 0.019\end{array}$

$\begin{array}{lll}1926 & 1.005 & 0.018\end{array}$

$\begin{array}{lll}1927 & 1.021 & 0.019\end{array}$

$\begin{array}{lll}1928 & 1.034 & 0.019\end{array}$

$1929 \quad 1.066 \quad 0.019$

$\begin{array}{lll}1930 & 1.047 & 0.019\end{array}$

1931

$\begin{array}{ll}1.108 & 0.019\end{array}$
Transitory Component

Parameter p.e. s.e.

$s_{c}$

1916-1924 $1.000 \quad-$

$\begin{array}{lll}1925 & 0.972 & 0.034\end{array}$

$\begin{array}{lll}1926 & 0.982 & 0.032\end{array}$

$\begin{array}{lll}1927 & 0.997 & 0.034\end{array}$

$\begin{array}{lll}1928 & 0.997 & 0.036\end{array}$

$1929 \quad 1.001 \quad 0.038$

$\begin{array}{lll}1930 & 1.029 & 0.042\end{array}$

$1931 \quad 0.964 \quad 0.044$ 


\begin{tabular}{|c|c|c|c|c|c|}
\hline 1932 & 1.042 & 0.019 & 1932 & 0.991 & 0.047 \\
\hline 1933 & 1.031 & 0.020 & 1933 & 0.997 & 0.051 \\
\hline 1934 & 1.019 & 0.022 & 1934 & 1.090 & 0.059 \\
\hline 1935 & 1.033 & 0.022 & 1935 & 1.043 & 0.061 \\
\hline 1936 & 1.020 & 0.021 & 1936 & 0.994 & 0.063 \\
\hline 1937 & 0.956 & 0.021 & 1937 & 1.022 & 0.068 \\
\hline 1938 & 1.013 & 0.022 & 1938 & 1.019 & 0.073 \\
\hline 1939 & 1.017 & 0.023 & 1939 & 0.997 & 0.076 \\
\hline 1940 & 1.027 & 0.023 & 1940 & 0.989 & 0.080 \\
\hline 1941 & 1.004 & 0.024 & 1941 & 1.078 & 0.091 \\
\hline 1942 & 0.964 & 0.024 & 1942 & 1.034 & 0.092 \\
\hline 1943 & 1.033 & 0.026 & 1943 & 1.022 & 0.096 \\
\hline 1944 & 1.072 & 0.027 & 1944 & 1.033 & 0.102 \\
\hline 1945 & 0.986 & 0.026 & 1945 & 1.066 & 0.109 \\
\hline 1946 & 1.036 & 0.028 & 1946 & 1.003 & 0.108 \\
\hline 1947 & 1.005 & 0.027 & 1947 & 1.004 & 0.112 \\
\hline 1948 & 1.007 & 0.028 & 1948 & 0.977 & 0.114 \\
\hline 1949 & 0.982 & 0.029 & 1949 & 1.021 & 0.123 \\
\hline 1950 & 1.024 & 0.030 & 1950 & 0.989 & 0.125 \\
\hline 1951 & 1.031 & 0.031 & 1951 & 1.002 & 0.131 \\
\hline 1952 & 1.010 & 0.031 & 1952 & 0.973 & 0.132 \\
\hline 1953 & 0.967 & 0.032 & 1953 & 0.993 & 0.138 \\
\hline 1954 & 0.950 & 0.032 & 1954 & 1.009 & 0.145 \\
\hline 1955 & 0.984 & 0.034 & 1955 & 0.999 & 0.148 \\
\hline 1956 & 0.950 & 0.034 & 1956 & 1.030 & 0.157 \\
\hline 1957 & 0.982 & 0.035 & 1957 & 0.946 & 0.150 \\
\hline 1958 & 1.024 & 0.037 & 1958 & 0.974 & 0.159 \\
\hline 1959 & 0.986 & 0.037 & 1959 & 0.994 & 0.167 \\
\hline 1960 & 1.044 & 0.040 & 1960 & 1.052 & 0.181 \\
\hline 1961 & 0.967 & 0.038 & 1961 & 1.014 & 0.179 \\
\hline 1962 & 0.972 & 0.038 & 1962 & 1.023 & 0.185 \\
\hline 1963 & 1.010 & 0.040 & 1963 & 1.039 & 0.193 \\
\hline 1964 & 0.970 & 0.040 & 1964 & 1.062 & 0.201 \\
\hline 1965 & 1.006 & 0.042 & 1965 & 1.092 & 0.212 \\
\hline 1966 & 1.009 & 0.043 & 1966 & 1.050 & 0.209 \\
\hline 1967 & 0.982 & 0.043 & 1967 & 1.083 & 0.220 \\
\hline 1968 & 1.057 & 0.046 & 1968 & 1.050 & 0.219 \\
\hline 1969 & 0.995 & 0.045 & 1969 & 1.048 & 0.223 \\
\hline 1970 & 0.955 & 0.044 & 1970 & 0.981 & 0.213 \\
\hline 1971 & 0.996 & 0.047 & 1971 & 1.014 & 0.225 \\
\hline 1972 & 0.983 & 0.048 & 1972 & 0.960 & 0.218 \\
\hline 1973 & 1.001 & 0.050 & 1973 & 0.925 & 0.214 \\
\hline 1974 & 1.028 & 0.058 & 1974 & 0.985 & 0.233 \\
\hline 1975 & 1.009 & 0.062 & 1975 & 0.940 & 0.226 \\
\hline 1976 & 1.007 & 0.075 & 1976 & 0.886 & 0.218 \\
\hline 1977 & 0.997 & 0.105 & 1977 & 0.901 & 0.226 \\
\hline $1978-1980$ & 1.000 & 0.149 & $1978-1980$ & 0.859 & 0.223 \\
\hline
\end{tabular}


Figure 1: Variances of log-wage with age, by birth-cohort.

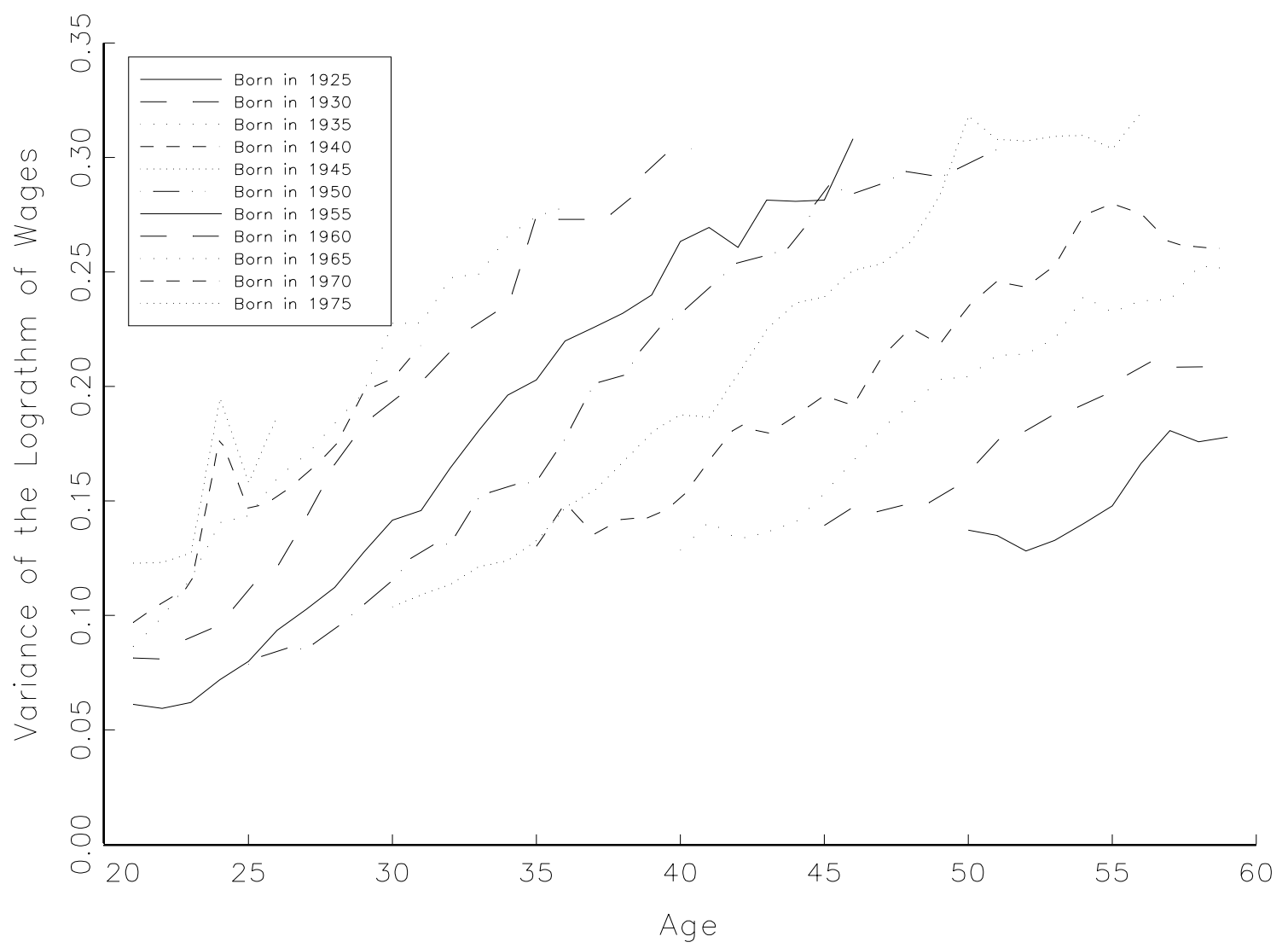

Figure 2: Variance-covariances of log-wages.

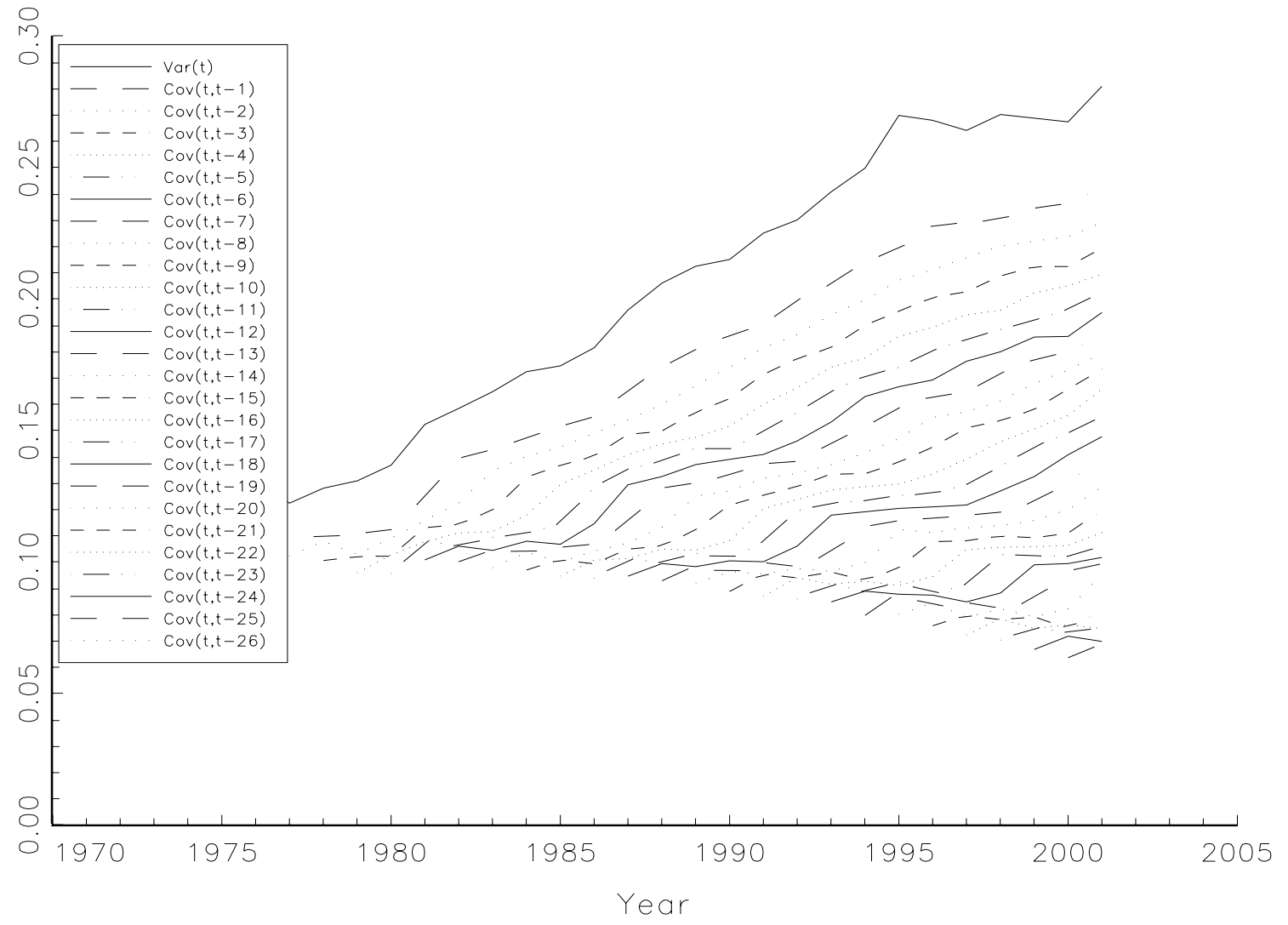


Figure 3: Correlations between two periods of log-wages.

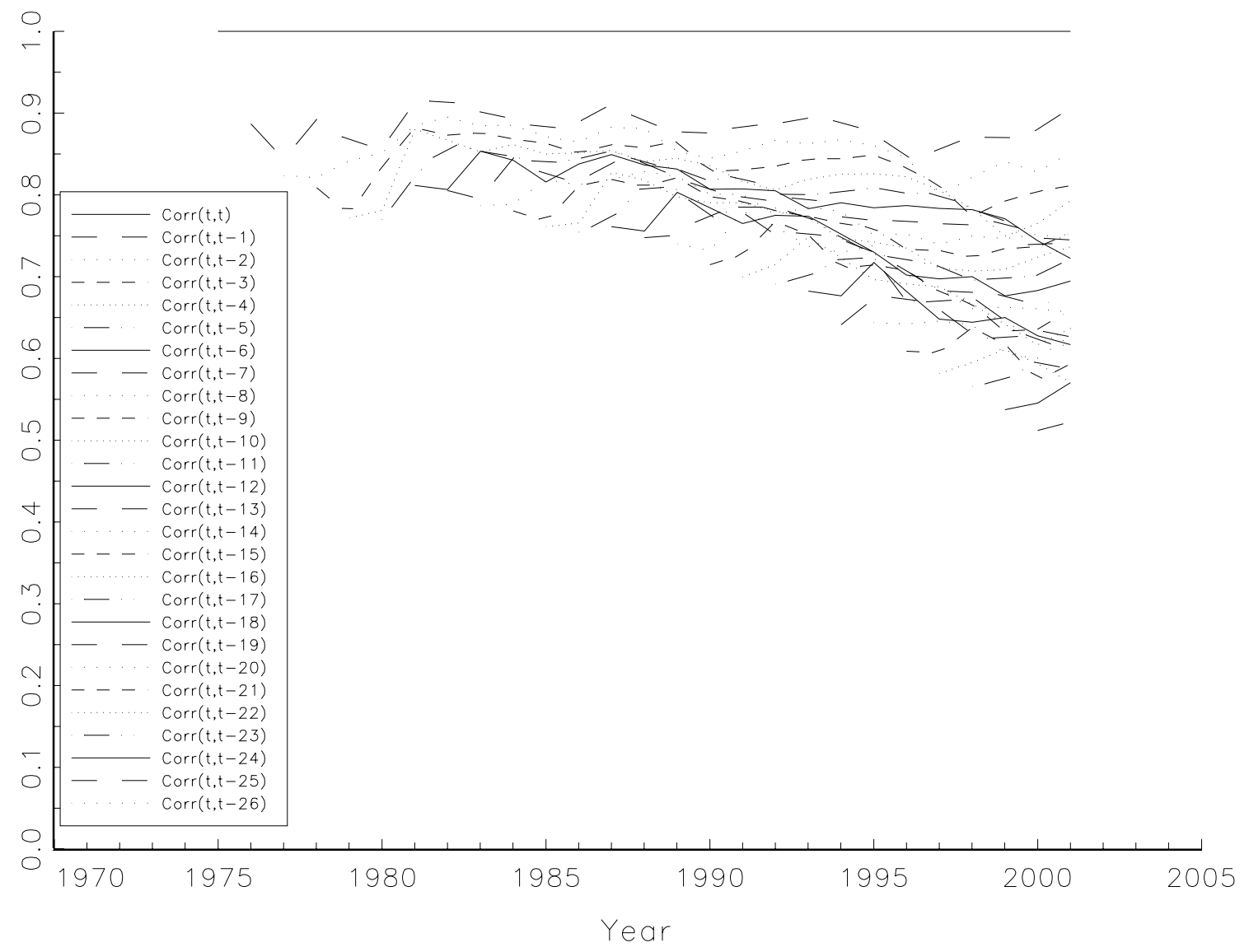

Figure 4: The estimated variances of the transitory and permanent components of logwages over the period 1975-2001.

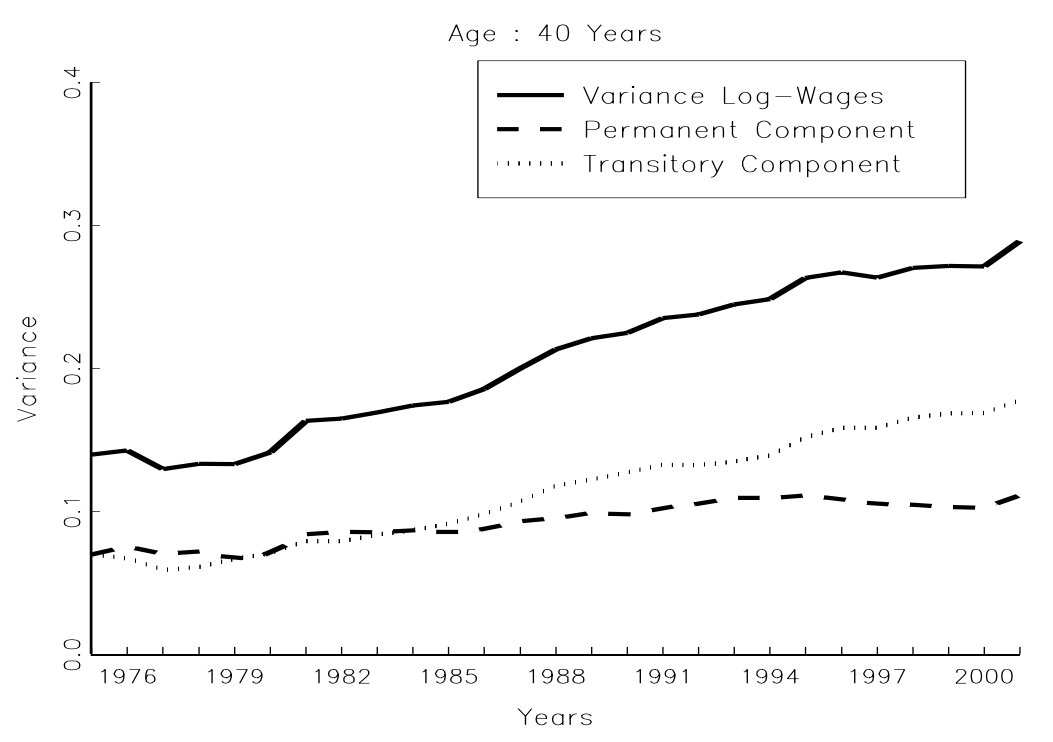


Figure 5: Wage immobility.

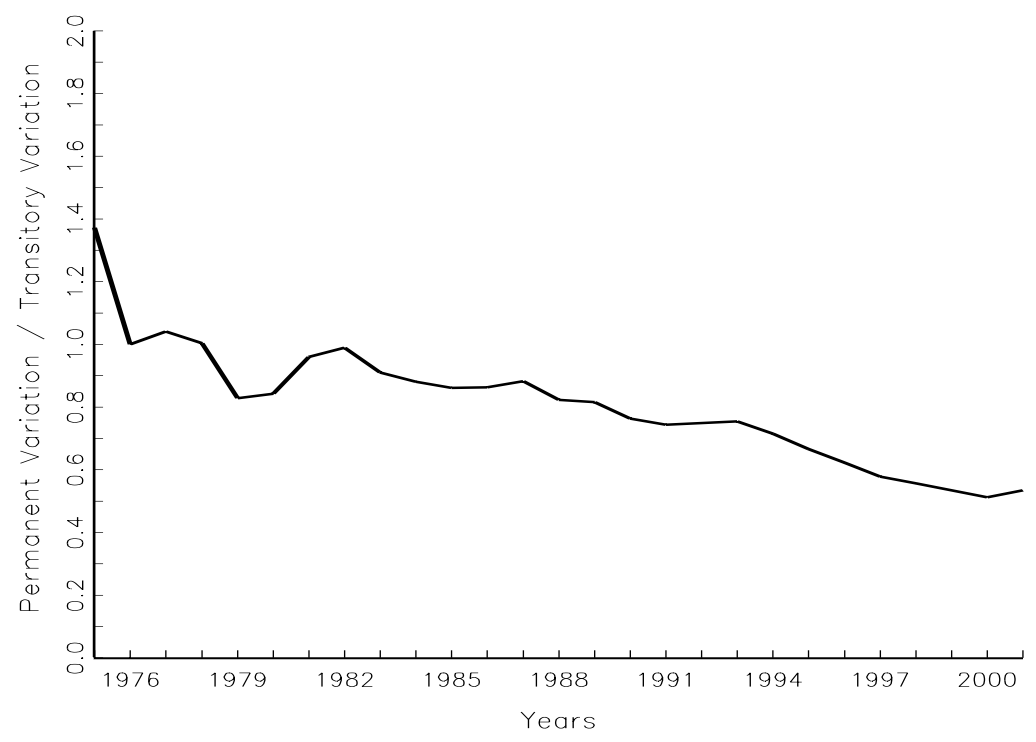

Figure 6: The variances of the transitory and permanent components of log-wages over individuals' lifecycle.

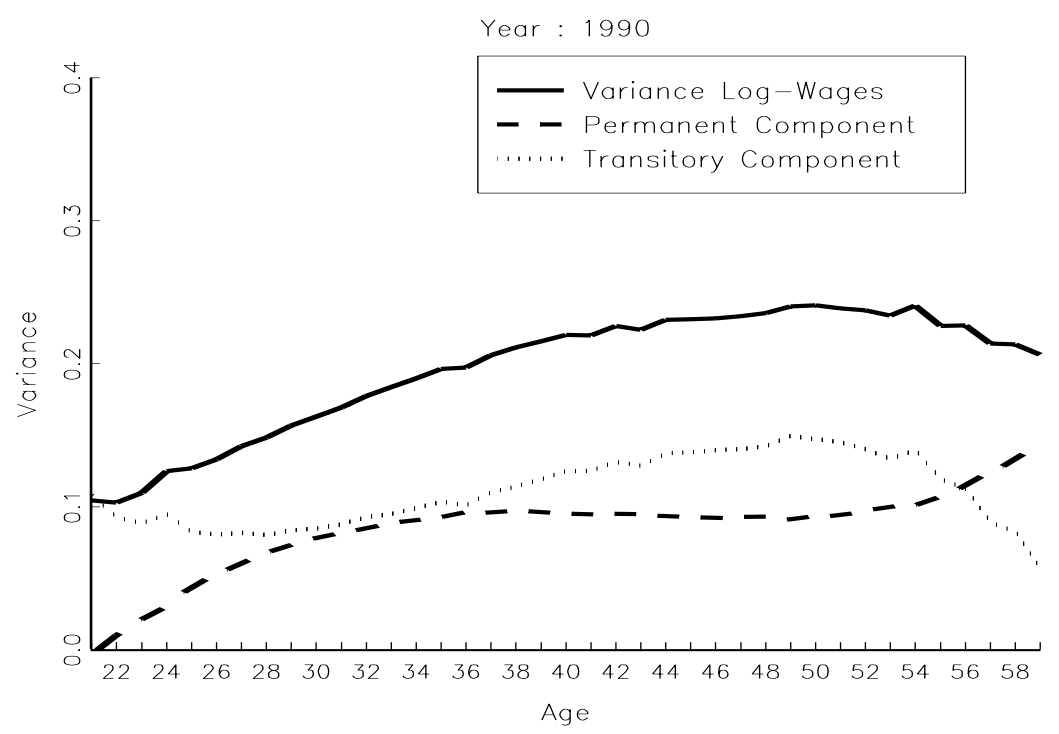


Figure 7: The permanent and transitory components of log-wages for the different cohorts, i.e. in the calendar years of turning 21 years of age.

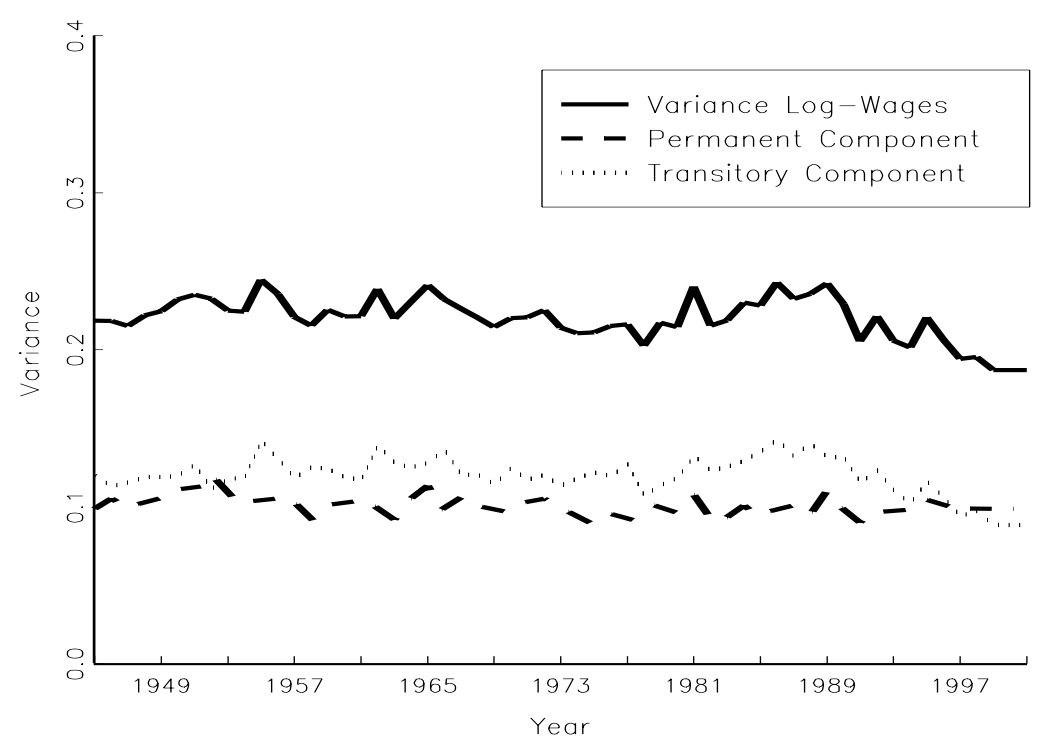

Figure 8: The estimated correlation coefficient.

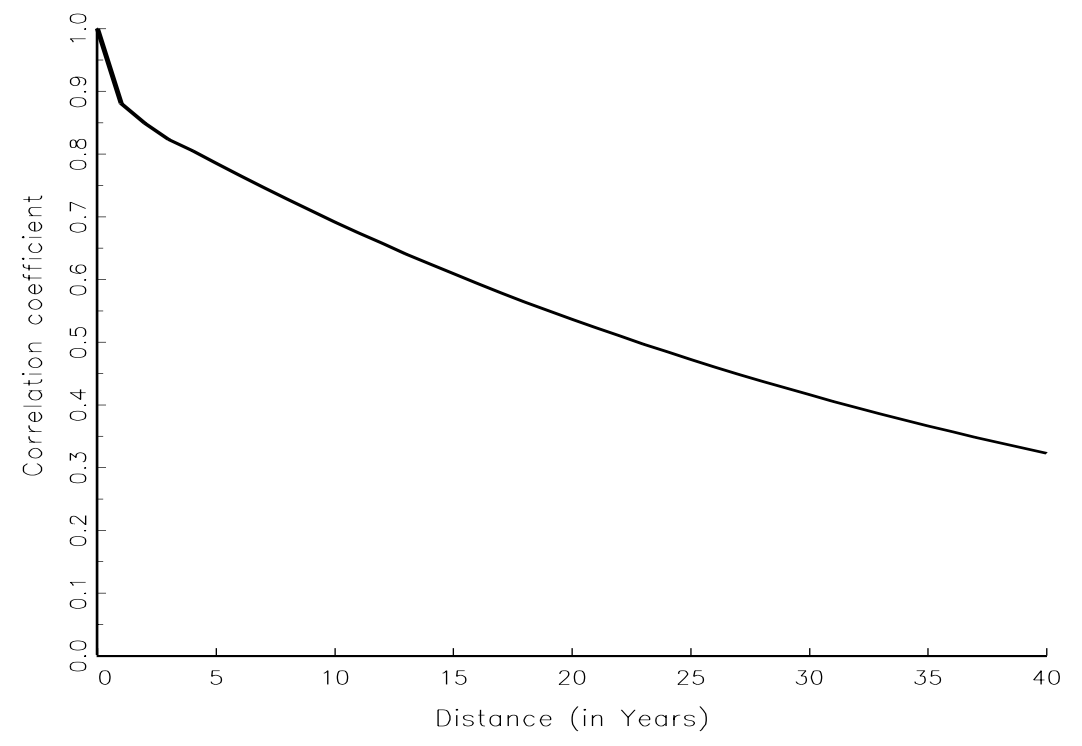


Figure 9: Ignoring cohort effects. The estimated variances of the transitory and permanent components of log-wages over the period 1975-2001.

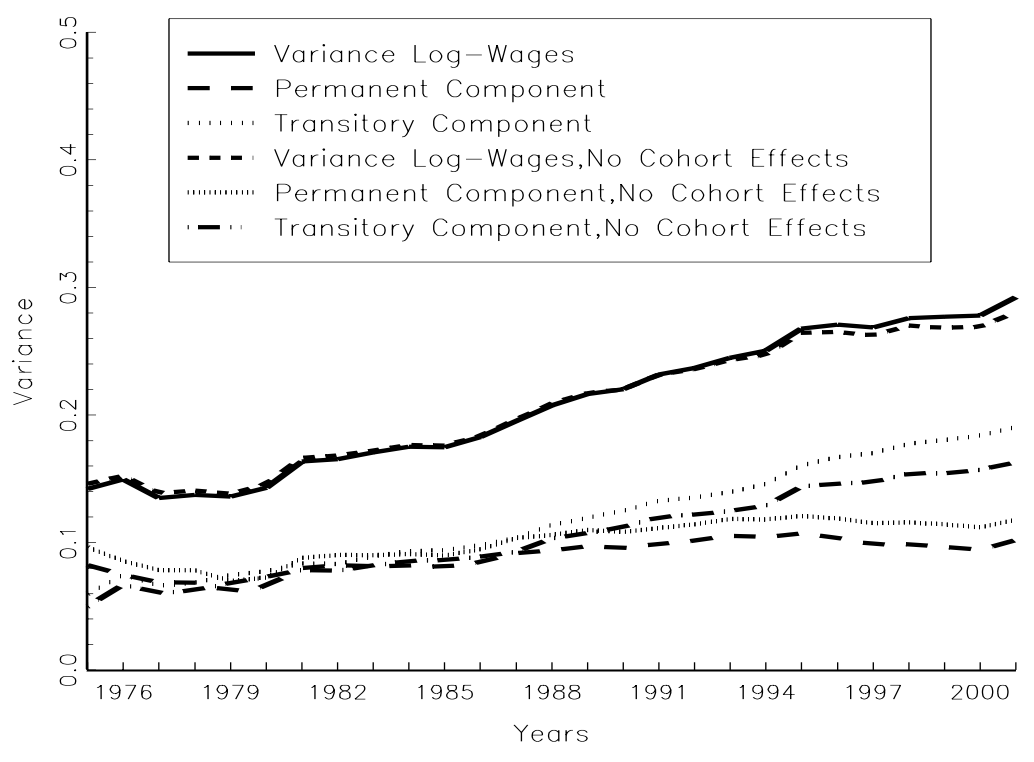

Figure 10: Ignoring cohort effects. The variances of the transitory and permanent components of log-wages over individuals' lifecycle.

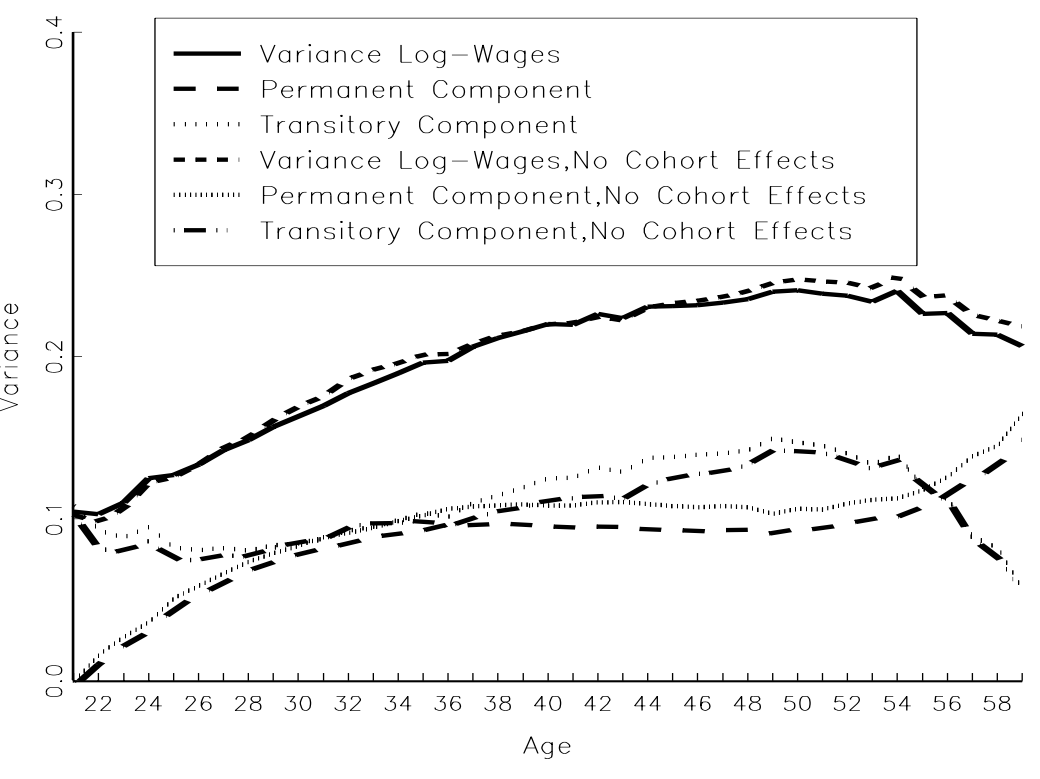


Figure 11: Ignoring cohort effects and age-specific transitory wage shocks. The estimated variances of the transitory and permanent components of log-wages over the period 1975-2001.

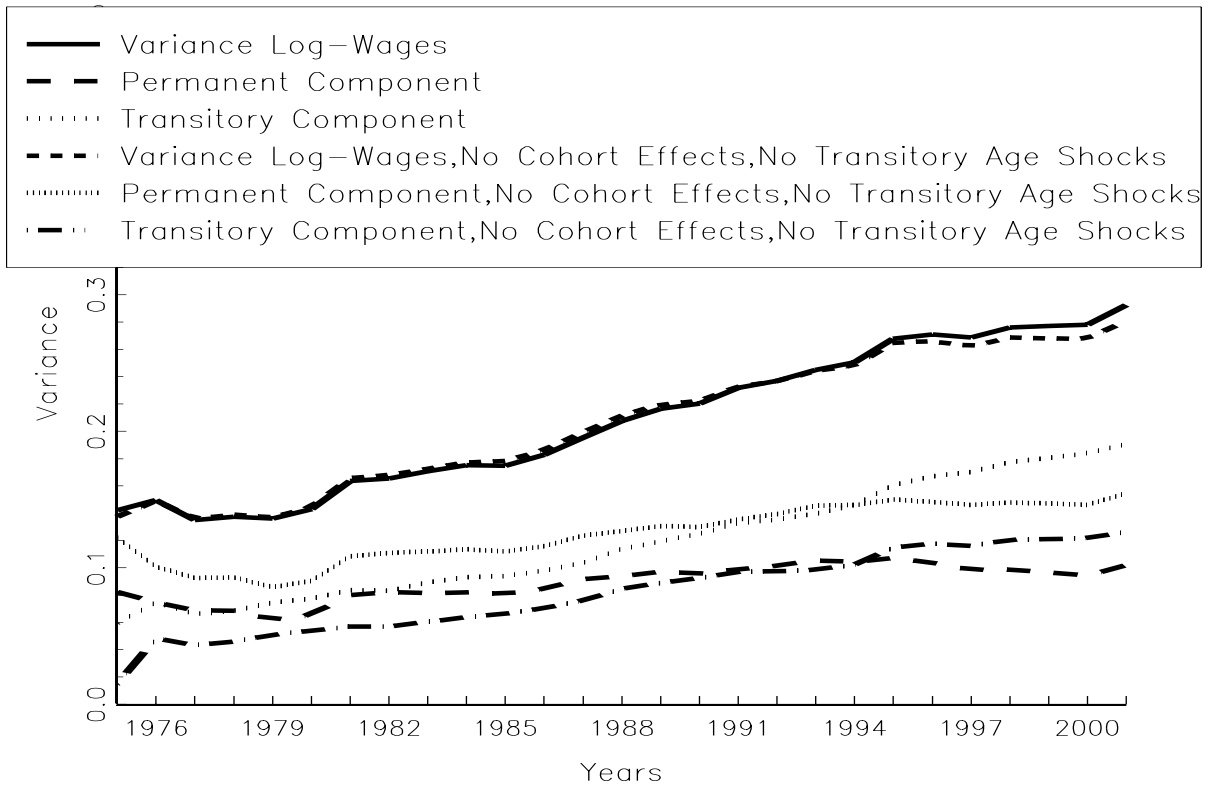

Figure 12: Ignoring cohort effects and age-specific transitory wage shocks. The variances of the transitory and permanent components of log-wages over individuals' lifecycle.

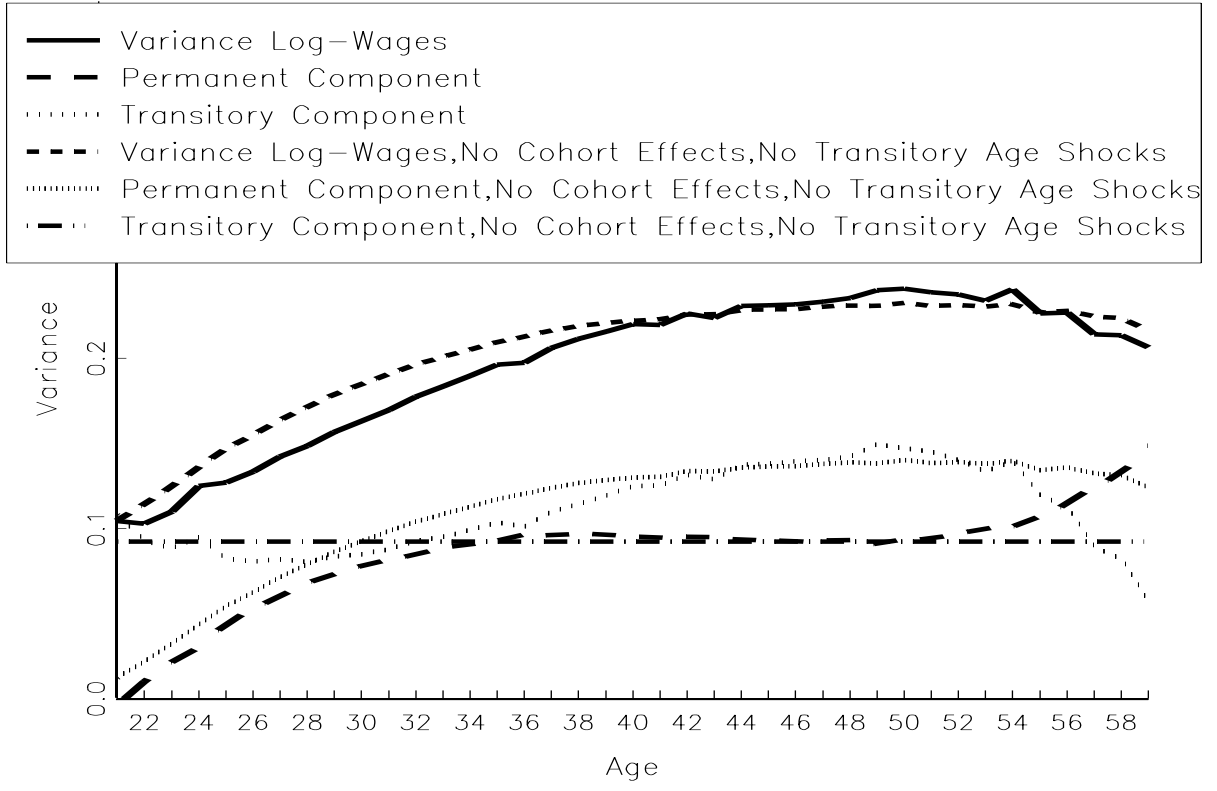

